\title{
Proposta de implementação de MRP I: estudo de caso em uma empresa de implementos rodoviários
}

Jadeilson Serafim de Andrade jadeilson.s.a@hotmail.com

nstituto Federal de Educação, Ciência e Tecnologia de Minas Gerais (IFMG), Governador Valadares, Minas Gerais,
Brasil

Tatielle Menolli Longhini tatielle.longhini@ifmg.edu.b Instituto Federal de Educação, Ciência Tecnologia de Minas Gerais (IFMG), Governador Valadares, Minas Gerais, Brasil

\begin{abstract}
RESUMO
Este trabalho é resultado de um estudo desenvolvido em uma empresa do setor industrial de implementos rodoviários e visa a implementação de um sistema de administração da produção, iniciando pela implementação do MRP I (Planejamento dos Recursos Materiais) para o controle de estoques de produção que funciona sob encomenda. Para o estudo foram selecionados os três produtos mais vendidos, onde se elaborou suas estruturas e listas de materiais para exemplificar como seria o resultado de um sistema ERP (Planejamento dos Recursos Materiais) no setor de Implementos Rodoviários. O estudo se classifica como sendo estudo de caso, na qual um assunto é estudado em profundidade, o objetivo da pesquisa é descritivo e tem natureza qualitativa-quantitativa. A coleta de dados foi feita por meio de observação direta, pesquisa documental. Após o estudo pôdese confirmar o que diversos autores dizem a respeito dos sistemas de administração da produção, sendo um recurso que integra os setores da organização e organiza as informações, agilizando o processo produtivo com informações mais rápidas e precisas, se tornando um diferencial as organizações que o aderem.
\end{abstract}

PALAVRAS-CHAVE: Planejamento e Controle da Produção. MRP I. ERP. 


\section{INTRODUÇÃO}

As mudanças que vieram após a revolução industrial exigem das empresas uma nova postura de atuação frente aos seus clientes, concorrentes, fornecedores e em relação à sua administração interna. Diante desse contexto, as empresas têm feito altos investimentos em certificações ISO (International Standart Organization), processos de reengenharia, sistemas de gestão empresarial integrado, produção enxuta, entre outras para aprimorar seus processos produtivos.

O Planejamento e Controle de Produção (PCP), é um conjunto de atividades inter-relacionadas que visa proporcionar informações a todo o processo produtivo, alinhando o fluxo de informações provenientes das mais diferentes áreas da empresa, como vendas, finanças, estoques, a empresa com um todo, sendo traçados parâmetros de funcionalidade entre diversos setores (BURBRIDGE, 1988; RUSSOMANO, 1995; PLOSSL, 1993; SLACK et al, 2002; CHIAVENATO, 2011; COSTA, 2010; CORRÊA et al., 2007).

Os resultados alcançados com o PCP são muitos: altos índices de produtividade e qualidade, menor quantidade de falhas e erros e, consequentemente, menores custos de produção, facilidade em atingir metas e objetivos traçados; maior assertividade nas decisões, melhor gerenciamento dos recursos disponíveis; melhoria do fluxo de informações e compatibilização dos diversos setores da empresa, e o mais importante, aumento da satisfação dos clientes. Em suma, o Planejamento e Controle da Produção leva a empresa a produzir com maior perfeição rapidez e menor custo, obtendo assim, maior lucratividade (LOPES; MICHELE, 2007, p.3).

Para isso, são implementados os métodos MRP I e II. O MRP I (Materials Requirements Planning) objetiva verificar todos os componentes necessários para a produção dos pedidos dos clientes nos prazos estabelecidos, de modo que se calcule o que será produzido, quantidade de material necessário e o momento em que serão utilizados (CORRÊA et al., 2000). Já o MRP II (Manufacturing Resources Planning) é um plano global para o planejamento e monitoramento de todos os recursos de uma empresa de manufatura (SLACK, 2009).

Com as implicações, devido ao tempo de resposta e a crescente importância do prazo de entrega ao cliente, surgiu também o ERP (Enterprise Resources Planning) que funciona como um sistema para tomada de decisões na empresa. Todos estes sistemas fomentaram uma grande revolução no Planejamento e Controle da Produção, forçando as empresas a reformularem os seus sistemas produtivos.

Segundo estudos de Oliveira e Hatakeyama (2012), os índices após a implementação do PCP tem uma representatividade de $70 \%$ de melhor integração dos processos, $20 \%$ a 37\% melhores práticas de negócio; 37\% racionalização/flexibilidade e competitividade; $30 \%$ melhor gestão da cadeia de suprimentos e $23 \%$ a $30 \%$ apoio nas estratégias de negócios.

Os fatores relacionados à implantação do PCP não se dão, apenas, das dificuldades tecnológicas, mas incluem também a sensibilidade e receptividade com que são tratadas as mudanças trazidas pelo sistema, os problemas de falta de comprometimento e as falhas na comunicação entre as pessoas envolvidas (AVISON; MALAURENT, 2007). 
Um dos principais e mais evidentes obstáculos é a mudança cultural na implementação. A falta de apoio e o comprometimento da alta direção, torna-se inviável qualquer projeto de implementação. Um ponto relevante é a cultura empresarial e como ela pode influenciar na implantação de sistemas MRP.

Devido à sua complexidade, altos custos de investimento, barreiras de implantação e imposição de mudanças radicais na organização, esses sistemas têm apresentado significativas falhas (LAW; NGAI, 2007). Um aspecto trivial para que o ERP alcance os objetivos organizacionais é o amadurecimento e preparação da empresa para as transformações, definindo claramente as necessidades e compatibilizando-as aos objetivos do negócio (ALOINI; DULMIN; MININNO, 2007; SAMMON; ADAM, 2010; LAW; NGAI, 2007).

Segundo Bento, Tambosi e Prus (2013), no setor automobilístico, o MRP permite maior flexibilidade, melhores resultados no planejamento de produção e de compras, também é importante para melhorar a qualidade das informações com fornecedores e clientes, reduzindo tempo de análise e decisão. Bento, Tambosi e Martin (2012) e Souza (2000) complementam que a tecnologia do MRP permite que as empresas trabalhem de maneira mais organizada e enxuta, obtendo, assim, máxima produtividade, alavancando os resultados e atenuando os custos.

Schuster e Tondolo (2014), Bragalia e Petroni (1999) e Ribeiro et al. (2015), afirmam que os resultados com a implantação do MRP são vários, tal como baixo tempo de processamento das informações, automatização do cálculo das necessidades de materiais, rapidez na reprogramação, melhoria do gerenciamento de estoques, redução dos desperdícios, atendimento dos prazos de entrega, diminuição do lead time (tempo de espera) do produto e geração de relatórios, tendo em vista a correta tomada de decisão. Isso tudo reflete diretamente, na melhoria de competitividade e ganho de qualidade em produto.

A proposta de pesquisa é a implantação do MRP I em uma indústria de implementos rodoviários. E como ela pode ajudar os administradores na tomada de decisão e planejamento.

Essa indústria desenvolve componentes complementares ao caminhão como: reboques, semi-reboques e carrocerias, responsáveis pela função específica de transporte de cargas. A versatilidade do setor permite que sejam obtidos os mais variados tipos de produtos, de acordo com a necessidade do transportador (GOLDENSTEIN, 2006).

Segundo a Confederação Nacional do transporte (Logística, 2019), o modal rodoviário representa cerca de $60 \%$ da matriz de transporte brasileira. Por atuar em um contexto em que o modal rodoviário é amplamente dominante e os transportadores de carga, os operadores logísticos esforçam-se para aumentar sua eficiência, os fabricantes de veículos de carga devem ser mais inovadores e apresentar produtos cada vez mais especializados e customizados (GOLDENSTEIN, 2006).

Nesse contexto, propõe-se a indústria de implementos rodoviários, localizada na cidade de Governador Valadares-MG, a utilização do sistema MRP, para melhor gestão de estoques e produção, bem como proporcionar melhor integração entre os setores produtivos da empresa e auxiliar a tomada de decisão. 
Portanto, esse estudo tem como objetivo a implantação de um MRP em uma indústria de implementos rodoviários. Assim, o problema de pesquisa é: Como o MRP I pode auxiliar na gestão produtiva em uma empresa de implementos rodoviários?

Assim, este trabalho tem como objetivo a aplicação do MRP em uma indústria de implementos rodoviários, situada na cidade de governador Valadares - MG. Para isso serão utilizadas como ferramentas metodológicas a pesquisa descritiva, de natureza qualitativa-quantitativa, como objeto de estudo - estudo de caso, quanto à técnica de coleta de dados, observação direta, documental e pesquisa-ação. Espera-se melhor planejamento e controle da produção da empresa.

\section{FUNDAMENTAÇÃO TEÓRICA}

Neste capítulo será definido o referencial do trabalho, onde será apresentado sobre Planejamento e Controle da Produção (PCP), sistemas de controle da produção (SAP) e sua evolução, e por fim sobre o Planejamento das Necessidades Materiais (MRP I).

\section{PLANEJAMENTO E CONTROLE DA PRODUÇÃO}

Segundo Erdmann (1994), o Planejamento e Controle da Produção (PCP) é a área da administração da produção que planeja, programa e controla as operações da produção. E isso vai desde o gerenciamento da matéria prima até a fabricação do produto.

Chiavenato (2005) afirma que o PCP é um processo que canaliza e absorve informações, com propósito de permitir a tomada de decisões sobre o que fazer, quando e quanto fazer em termos de produção. Tornando possível planejar máquinas e equipamentos, materiais e pessoas para o processo produtivo.

Já para Slack, Chambers e Jhonston (2009), o planejamento e controle é uma ligação entre as necessidades do mercado e o que as operações podem fornecer. O PCP é responsável pelo fornecimento de sistemas, procedimentos e decisões que visam conciliar as diferentes ofertas e demandas do mercado.

Paralelamente, Martins e Laugeni (2005) afirmam que se trata de um sistema que faz a transformação das informações da organização, pois recebe dados sobre a quantidade de estoque, a previsão de vendas, a forma de produção dos produtos e a capacidade produtiva. O PCP tem o objetivo de transformar as informações recebidas em ordens de produção.

A longo prazo, os gestores da produção fazem planos referentes ao que eles pretendem fazer, quais os recursos eles precisam e os objetivos que esperam atingir. O foco está mais no planejamento do que no controle, porque ainda existe pouco a ser controlado. Eles vão usar previsões da demanda provável, descritas em termos agregados (SLACK et al., 2002).

O planejamento e controle de médio prazo estão preocupados com planejar em mais detalhes (e replanejar, se necessário). Eles olham para frente para avaliar a demanda global que a operação deve atingir de forma parcialmente desagregada (SLACK et al., 2002). Já no planejamento e no controle a curto prazo, 
muitos dos recursos terão sido definidos e será difícil fazer mudanças de grande escala no uso dos recursos. Todavia, intervenções a curto prazo são possíveis se as coisas não correm conforme os planos. Nesse estágio, a demanda será avaliada de forma totalmente desagregada (SLACK, CHAMBERS, JOHNSTON, 2009).

Já Chiavenato (2005) afirma que o PCP trabalha monitorando o processo produtivo e divide-se em quatro fases. São elas: (i) projeto de produção que visa estabelecer o que será produzido e quando será produzida; (ii) coleta de informações sobre todos os setores de uma indústria para que tenha o desempenho necessário durante a produção; (iii) planejamento e controle da produção que busca informações a respeito da linha produção, estoques; (iv) mão de obra disponível, para que seja possível produzir tudo o que foi projetado.

\section{SISTEMAS DE ADMINISTRAÇÃO DA PRODUÇÃO}

Sistemas de Administração da Produção (SAP) é o nome genérico que se dá aos sistemas de informação, que servem de apoio à tomada de decisões táticas e operações, referentes às seguintes questões básicas: o que produzir, quanto produzir, quando produzir e com que recurso produzir. O proposito dessas decisões é atingir os objetivos estratégicos das organizações (CORRÊA et al., 2000) e (BALLOU, 2010). O sistema SAP centraliza e integra todos os sistemas da empresa (vendas, estoque, compras, operações, finanças, dentre outros) sendo possível realizar buscas detalhadas de dados completos e atualizados, atendendo às necessidades dos clientes com mais rapidez.

Os sistemas SAP são flexíveis e ajustáveis para atender as necessidades da organização, auxiliando diretamente na tomada de decisão ao excluir redundância na entrada de dados, erros e custos. O que proporciona um melhor aproveitamento a partir de obtenção de resultados mais sólidos (RIBEIRO, 2016).

O ponto chave nesta definição é a necessidade gerencial de usar as informações para tomar decisões inteligentes. Segundo Cristopher (1997), de nada vale simplesmente automatizar os processos manuais, por processos computadorizados, sem que se auxilie a tomada de decisão, pois estaríamos automatizando a ineficiência da informação.

O SAP não é responsável pela tomada de decisões, nem mesmo pelo gerenciamento de sistemas. Este é um papel que cabe aos administradores, que têm no SAP o suporte para executar suas funções de forma adequada. De acordo com Tubino (2000), apesar da informatização, o acompanhamento dos processos por pessoas qualificadas é fundamental para a identificação de gargalos, e na organização de planos de produção consistentes e confiáveis.

\section{Evolução do SAP}

Nos anos 1950 (1950-1959), os sistemas de informação eram usados para manutenção de registros, processamento de transações, contabilidade e alguns aplicativos simples de processamento eletrônico de dados (Eletronic Data Processing- EDP) (LUTOSA et al., 2008). 
Na década de 1960 surgiu um novo conceito de sistema de informação gerencial (SIG), com capacidade para gerar relatórios gerenciais predefinidos, com a finalidade de auxiliar o grupo gerencial no processo de tomada de decisões. Nessa época, os sistemas de manufatura eram soluções personalizadas e desenvolvidas dentro de cada empresa, e tinham o foco no controle de estoque (LUTOSA et al., 2008).

Segundo Corrêa, Gianesi e Caon (2001), na década de 70 foi iniciada a evolução de softwares, sendo assim a base para o surgimento dos sistemas ERP. Estes passaram a conter mais módulos e funcionalidades, tornando-se ferramentas fundamentais para o acompanhamento e adequação da organização ao mercado, auxiliando as tomadas de decisões sob aspectos organizacionais.

Paralelamente, nessa época, surgia o MRP (Material Requirements Planning), que exerceu papel básico para o Planejamento e Controle da Produção. Os sistemas MRP dessa época ainda não tinham integração com outras áreas da empresa e eram exclusivamente para cálculos das necessidades de matériasprimas e intermediários (instante e quantidade à serem repostos), a partir das quantidades de produtos finais que se desejava produzir, sem analisar a capacidade disponível existente (LUTOSA et al., 2008). Para Norman (1983, pag.213), "a essência do MRP I é que se trabalha atrás da demanda (o cliente) para determinar os materiais e outras exigências".

Na década de 1980, intensificou-se o uso dos microcomputadores pelos usuários finais, devido à evolução acelerada da capacidade de processamento dos aparelhos e ao surgimento de softwares de redes de comunicações, além da baixa dos preços de hardwares. Com isso, os usuários finais deixaram de depender excepcionalmente dos departamentos de tecnologia de informação das empresas para terem suas necessidades de trabalho atendidas. Paralelamente, o sistema de suporte a decisão (Decision Support System- DSS) evolui para sistema de informação executiva (do inglês Executive Information System- EIS), que apresentava um novo modo de gerar informações críticas de modo simplificado no instante e formato estabelecidos pelo usuário (LUTOSA et al., 2008).

A partir da década de 1980, começaram a surgir diferentes formas de automação industrial que foram amplamente utilizadas para aumentar a eficiência da manufatura. As ferramentas Computer Aided Design (CAD) / Computer Aided Engeneering (CAE), são consideradas como formas de automação de projeto e engenharia. Nesse momento as técnicas de inteligência artificial (IA), bem como os sistemas especialistas (Expert Systems - ES) começaram a ser difundidos (LUTOSA et al., 2008). Houve a evolução do MRP para o planejamento dos recursos de manufatura (do inglês Manufacturing Resources Planning - MRP II).

O MRP II representou o primeiro passo para a integração entre as áreas funcionais das empresas, que ocorreu no fim da década de 1980 para 1990, com o aparecimento dos sistemas integrados de gestão empresarial (ERP). O MRP II permitia a conexão da base de dados criada e mantida pelo MRP com o sistema financeiro da organização para a geração de relatórios e para permitir que outras áreas testassem prováveis cenários de decisões, tais como: projetar valores futuros de recebimento, de custo de produtos, de alocação de mão-de-obra, de pedidos em carteira e de lucro entre outros (CORRÊA; GIANESI ,1994). 
Essas informações eram utilizadas, por exemplo, pelas áreas de produção, compras, marketing, finanças e de engenharia para desenvolver e monitorar o planejamento estratégico, determinar os objetivos de vendas, as competências de produção, bem como as restrições de fluxo de caixa. A partir de então, os sistemas de informação começam a exercer um papel estratégico nas organizações, passando a contribuir com a melhoria dos processos, produtos e serviços, atuando como facilitador na obtenção de vantagens competitivas (LUTOSA et al., 2008).

Na década de 1990, a junção do MRP II e os demais sistemas especialistas em uma base de dados única "explodiram", dando origem aos sistemas integrados de gestão empresarial ERP (Enterprise Resource Planning). Esses sistemas representaram uma revolução para o tratamento dos processos internos das empresas, pois, além de abolirem com a redundância de informações mantidas por diversas áreas, que muitas vezes eram divergentes (CORRÊA et al., 2001).

Por não estar armazenado em um banco de dados unificado, esse sistema permitiu que as informações fossem transacionadas em tempo real, entre as áreas afins da organização, que resultou em um melhor entendimento de seus próprios negócios, sendo possível a adoção e reunião das melhores práticas de gestão, utilizadas no mercado para elaboração dos sistemas de ERP.

\section{Planejamento das Necessidades de Materiais}

Segundo Corrêa e Gianesi (1994), o Planejamento das Necessidades de Materiais (MRP I) é baseado em registros que demonstra a posição e os planos que dizem respeito à produção de estoque de cada item da organização, seja ele matéria-prima, semiacabado ou acabado. Pode-se considerar o MRP um Sistema de Administração de Produção (SAP) de grande valor, o mais implantado nas organizações ao redor do mundo, desde os anos 1970.

Para Guerra, Silva e Tondolo (2014), quanto à funcionalidade do MRP, podese perceber que a ferramenta propicia melhor percepção da estrutura do produto; lista de materiais agrupadas por itens que permite um melhor gerenciamento; identificação do lead time dos produtos; controle informatizado dos estoques; informação em tempo real; uniformidade da informação com todos os setores de produção; agilidade na emissão das ordens de compras e de produção; agilidade na tomada de decisão; e facilidade para programação e controle de produção.

Fernandes e Godinho (2007) afirmam que o MRP permite a determinação do que, quanto e quando produzir e comprar os diversos itens semiacabados, componentes e matérias-primas, levando em consideração a produção dos produtos finais. Por isso, para o desenvolvimento de um MPR I, sugere-se integrar informações sobre estoque existente, pedidos em carteira, previsão de vendas estrutura de produto entre outas como pode ser observado na Figura 1. 
Figura 1: visão geral do programa MRP

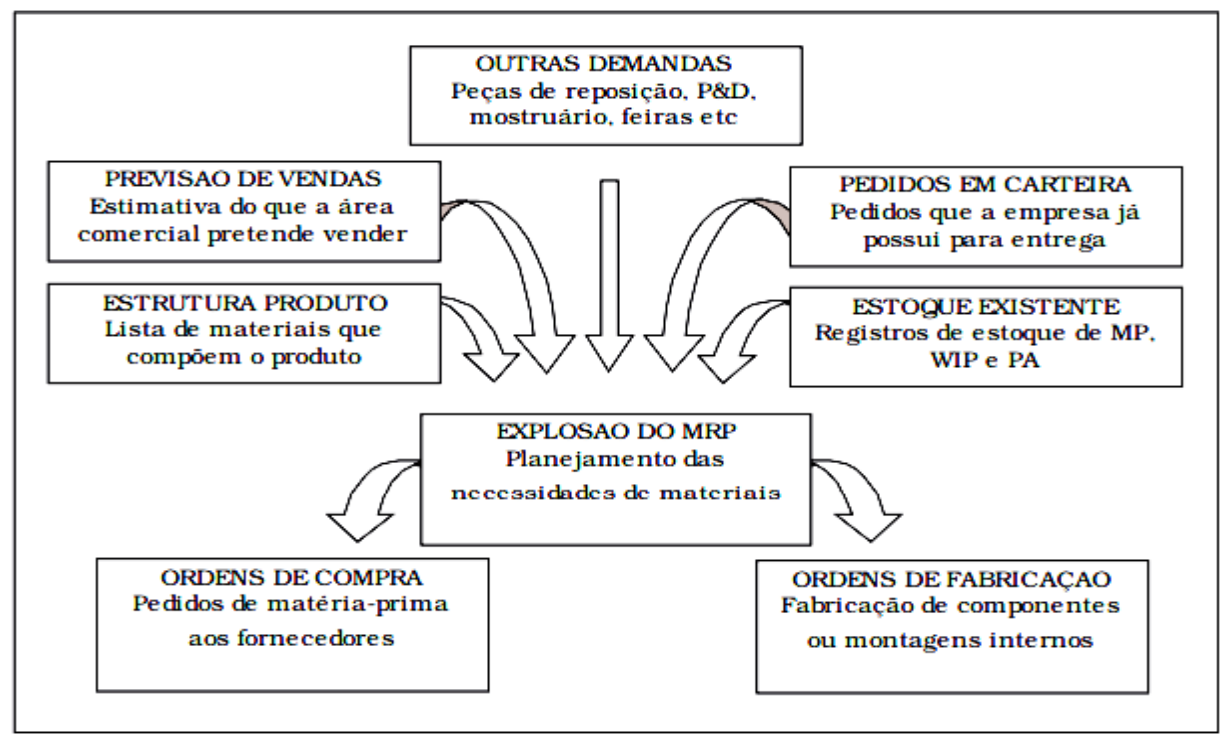

Fonte: Peinado e Graeml (2007)

As informações necessárias para processar o MRP, segundo Slack et al. (2009), assim como alguns de seus resultados, são:

Carteira de pedidos: também denominado pedidos em carteira, são pedidos para os quais já existe uma confirmação do cliente. Na linguagem empresarial são conhecidos como "pedidos firmes". Refere-se a pedidos firmes programados para algum momento no futuro, seu gerenciamento é função do departamento de vendas. A carteira de pedidos contém informações sobre cada pedido de cada cliente, para o MRP é de grande importância os registros do que cada cliente pediu, sua quantidade e o momento. Contudo, a probabilidade de várias mudanças nos pedidos dos clientes, fica evidente que a gestão da carteira de pedidos é um processo dinâmico e complexo.

Previsão de vendas: trata-se da expectativa de possíveis pedidos de vendas, que ainda não estão aprovados. Por mais aprimorado que seja o processo de previsão de uma organização, prever futuras tendências, ciclos ou sazonalidades é sempre uma tarefa muito complicada. Embora seja desejável que a produção reduza ou elimine sua dependência de previsões, muitas empresas não têm alternativas, pois seus sistemas de planejamento e controle dependem fortemente da precisão das previsões. E, devido à concorrência oferecer prazos de entrega cada vez menores, as demais empresas são forçadas a oferecerem também prazos menores para manterem competitivas.

Programa mestre de produção (MPS): É a fase mais importante do planejamento e controle de uma organização, constituindo-se como principal informação para o MRP. Para Martins e Laugeni (2005), o MPS retrata a demanda a ser atendida, ou seja, aquilo que realmente será produzido, contudo, por ser uma previsão, o MPS contém incertezas quanto ao futuro. Em seguida, o MRP verifica as possibilidades de alteração nas demandas previstas, fazendo seus cálculos diariamente.

Lista de materiais: É considerada a parte mais complicada do projeto pois todos os produtos a serem produzidos são "explodidos" em todos seus componentes, subcomponentes e peças. O ideal é que toda organização obtenha 
uma lista de materiais unificada devido às mudanças tecnológicas e exigências do mercado essas listas sofrem alterações constantemente. A complexa tarefa de mantê-las atualizadas é de responsabilidade do departamento de engenharia. (MARTINS; LAUGENI, 2005).

Um aspecto importante para compreender o sistema MRP é saber diferenciar o tipo da demanda, que pode ser dependente ou independente. "O entendimento sobre ambas facilitará a programação de fornecedores e da fabricação, principalmente quando se tratar de itens críticos, com longo lead time (tempo de reposição) de fabricação" (SOLON; FINOTTI, 2010, p.6).

Segundo Corrêa e Gianesi (1994), a diferença básica entre os itens de demanda independente e dependente, é que a demanda independente deve ser prevista com base nas características do mercado consumidor. Por outro lado, a demanda dependente não necessita ser prevista, pois pode apenas ser calculada a partir da demanda independente. De acordo com Guerra, Silva e Tondolo (2014), o sistema MRP ajuda os planejadores a identificar qual o melhor momento para comprarem ou produzir, com a finalidade de acabar com possíveis problemas causados por falta de insumos nas linhas de produção.

Resumidamente, Slack et al. (2009) e Dias (2005) afirmam que o processo de cálculo do MRP "explode" as necessidades dos itens de nível mais alto, através das listas de materiais, considerando os estoques e lead time (tempo de espera) de cada nível. Posteriormente, o MRP faz a programação para trás, gerando os planos, as ordens de produção e as ordens de compras.

Segundo Slack et al. (2009) para realização dos cálculos de quantidade e tempo descritos, os sistemas de MRP exigem que as empresas alimentem certos dados em arquivos de computador, quando o programa é rodado, esses dados são verificados e atualizados.

\section{PROCEDIMENTOS METODOLÓGICOS}

Este capítulo tem objetivo de apresentar a metodologia, que é um conjunto de procedimentos utilizados para chegar aos objetivos (GONSALVES, 2007). Será apresentada a classificação da pesquisa quanto aos objetivos da pesquisa, à natureza da pesquisa, escolha do objeto de estudo, além das técnicas de coleta de dados, e o plano de análise dos dados.

Com relação aos objetivos do estudo, a pesquisa se classifica como descritiva, que tem como objetivo principal descrever as características do que está sendo pesquisado ou estudado (GIL, 2010). Logo, esta pesquisa visa descrever as características de um sistema MRP, que será implantado em uma indústria de implementos rodoviários.

Quanto à natureza, a pesquisa se classifica em qualitativa-quantitativa (mista). Segundo Gerhardt e Silveira (2009), a pesquisa qualitativa não se preocupa com dados numéricos, mas, sim, com o aprofundamento da compreensão no que está sendo estudado. Já Fonseca (2002, p. 20) cita que, diferentemente da pesquisa qualitativa, os resultados da pesquisa quantitativa podem ser quantificados. A combinação destes dois tipos de pesquisa "pode ocorrer em diversos estágios: coleta, análise e/ou interpretação dos dados" (CRESWELL, 2010, p. 243). 
Fonseca $(2002$, p. 20) também afirma que "a utilização conjunta da pesquisa qualitativa e quantitativa permite recolher mais informações do que se poderia conseguir isoladamente". Por isso, o estudo se classifica como qualitativo devido ao aprofundamento do estudo do MRP, e do processo de produção da empresa que se deseja implementar o MRP, e quantitativo pois foi feito um levantamento dos implementos mais vendidos para o início da implantação do sistema MRP assim como os cálculos das necessidades de matérias.

Quanto ao objeto, classifica-se como um estudo de caso. Conforme Gil (2010), este se caracteriza pelo estudo profundo e exaustivo, de um ou diversos componentes, permitindo conhecimento amplo e detalhado sobre o mesmo. Ou seja, ele permite conhecer em profundidade o como e o porquê de uma determinada situação que se supõe ser única em diversos aspectos, buscando descobrir o que há nela de mais essencial e característico (GIL, 2010, p. 54). Ressalta-se que o trabalho, analisa uma situação de uma empresa de implementos rodoviários especificamente no setor de planejamento da produção, onde se deseja melhores resultados.

A coleta de dados ocorreu por meio de observação direta, pesquisa documental e pesquisa-ação. Por observação direta entende-se como sendo uma técnica que ocorre através do uso dos sentidos. Assim, nesta pesquisa a observação ocorreu através de visitas técnicas para conhecer a empresa na qual se realizou o trabalho. A observação pode ocorrer de três modos diferentes: observação simples, participante e sistemática. Nesta pesquisa realizou-se a observação simples do processo produtivo da empresa, onde o pesquisador apenas observou de maneira espontânea os fatos lá ocorridos, sem interferir no processo (GIL, 2010).

A pesquisa documental é similar à bibliográfica (desenvolvida com base em material, como livros e artigos científicos). A diferença está na natureza das informações, pois estas ainda não receberam um tratamento analítico, ou que ainda podem ser manipulados de acordo com os objetos da pesquisa, além de analisar os documentos de arquivos, etc. Existem também aqueles dados que já foram modificados, mas podem receber outras interpretações, como relatórios de empresas, tabelas etc. (GIL, 2010). Na pesquisa será analisado os contratos de vendas, para escolha dos equipamentos com maior índice de vendas para serem estudados, e os respectivos projetos dos mesmos, para a criação de listas de materiais a partir de seus projetos estruturais.

A pesquisa-ação é uma pesquisa com base empírica que é concebida e realizada em estreita associação com uma ação ou com a resolução de um problema coletivo, no qual os pesquisadores e os participantes que representam a situação ou problema estão envolvidos de modo a cooperar ou participar (THIOLLENT, 2008). Ao mesmo tempo em que o pesquisador trabalhava na empresa, ele também planejava o estudo e o executava com foco em obter melhorias com a implantação do MRP. Ainda, pela pesquisa-ação é possível estudar de modo dinâmico os problemas, decisões, ações, negociações, conflitos e tomadas de decisão que ocorrem entre o grupo durante o processo de transformação da situação (THIOLLENT, 2008).

Quanto às técnicas de análise de dados, fez-se a triangulação que, segundo Günther (2006), utiliza- se de diferentes abordagens metodológicas do estudo afim de prevenir possíveis distorções relativas tanto à aplicação de um único 
método quanto a uma única teoria ou um pesquisador. Denzin e Lincoln (2006), alegam que o "uso de múltiplos métodos, ou da triangulação, reflete uma tentativa de assegurar uma compreensão em profundidade do fenômeno em questão" (2006, p. 19). Para eles, a triangulação e uma forma de validar o estudo. Como foram analisados diferentes autores para a formulação desse trabalho a análise de dados se deu por triangulação, o quadro 1 mostra o resumo dos processos metodológicos utilizados nesse trabalho.

Quadro 1 - Resumo processos metodológicos

\begin{tabular}{|c|c|c|}
\hline Classificações & Caracterização & Autores \\
\hline $\begin{array}{l}\text { Objetivos de } \\
\text { pesquisa }\end{array}$ & $\begin{array}{l}\text { Descritiva- Descrever as características do que está } \\
\text { sendo pesquisado ou estudado. }\end{array}$ & Gil (2010) \\
\hline $\begin{array}{l}\text { Natureza da } \\
\text { pesquisa }\end{array}$ & $\begin{array}{l}\text { Qualitativa-quantitativa (mista) - é a utilização dos } \\
\text { métodos qualitativo e quantitativo sendo possível não só } \\
\text { compreensão do estudo, mas também a análise dos } \\
\text { dados. }\end{array}$ & $\begin{array}{l}\text { Gerhardt e } \\
\text { Silveira } \\
\text { (2009), } \\
\text { Fonseca } \\
\text { (2002) }\end{array}$ \\
\hline $\begin{array}{l}\text { Objeto de } \\
\text { estudo }\end{array}$ & $\begin{array}{l}\text { Estudo de caso - permite conhecer em profundidade o } \\
\text { como e o porquê de uma determinada situação que se } \\
\text { supõe ser única em diversos aspectos, buscando } \\
\text { descobrir o que há nela de mais essencial e } \\
\text { característico. }\end{array}$ & (Gil (2010) \\
\hline $\begin{array}{l}\text { Técnica de } \\
\text { coleta de } \\
\text { dados }\end{array}$ & $\begin{array}{l}\text { Observação direta- técnica que ocorre através do uso } \\
\text { dos sentidos, ou seja, o pesquisador apenas observa os } \\
\text { fatos. } \\
\text { Pesquisa documental - desenvolvida com informações } \\
\text { que ainda não receberam um tratamento analítico. } \\
\text { Pesquisa-ação - A pesquisa-ação é uma pesquisa com } \\
\text { base empírica que é realizada em associação com uma } \\
\text { ação ou com a resolução de um problema. }\end{array}$ & $\begin{array}{l}\text { Gil (2010), } \\
\text { Thiollent } \\
\text { (2008) }\end{array}$ \\
\hline $\begin{array}{l}\text { Análise de } \\
\text { dados }\end{array}$ & $\begin{array}{l}\text { Triangulação - é a utilização de diferentes abordagens } \\
\text { metodológicas do estudo afim de prevenir possíveis } \\
\text { distorções relativas tanto à aplicação de um único } \\
\text { método quanto a uma única teoria ou um pesquisador. }\end{array}$ & $\begin{array}{l}\text { Günther } \\
\text { (2006) }\end{array}$ \\
\hline
\end{tabular}

Fonte: Autoria própria.

Para a elaboração deste trabalho foi realizada uma visita a empresa para propor alguma melhoria, forma relatados pelos funcionários problemas no estoque e também falta de controle de matéria prima na produção. Sendo assim, foi proposto a implementação do MRP I, a partir da seleção dos implementos com maior representatividade de vendas conforme consta no registro de vendas da empresa nos últimos 12 meses. Com isso, foi elaborada a estrutura (listas de materiais) dos implementos, com auxílio de software $C A D^{\circledR}$, para posterior cadastro de todos os itens que compõem esses implementos no sistema de ERP MAXIPROD ${ }^{\circledR}$

\section{ESTUDO DE CASO}

A empresa, objeto de estudo, está localizada na cidade de Governador Valadares-MG, presente no mercado há mais de sessenta anos, atualmente no 
segmento de implementos rodoviários e prestação de serviços, conta com uma ampla linha de produtos e serviços. É classificada como empresa de pequeno porte (de 20 a 99 empregados), no qual conta com 30 colaboradores, e possui produção puxada (demanda gerada pelo cliente). Destacam-se como matériasprimas o aço e seus derivados, borracha e plástico.

O mercado de implementos rodoviários é bastante amplo e possui diversas fábricas espalhadas pelo Brasil. As principais produtoras localizam no sul e sudeste do país (FIGURA 2), e essas empresas tendem a se concentrar próximas aos maiores mercados. As grandes montadoras de caminhões como MercedesBenz, Iveco, Ford, Scania e Volvo, por exemplo localizam-se nessas regiões. Estar próximo ao mercado consumidor representa economia de custos logísticos e propicia melhor relação com os clientes.

Figura 2: Quantidade de fabricas de implementos rodoviários no brasil

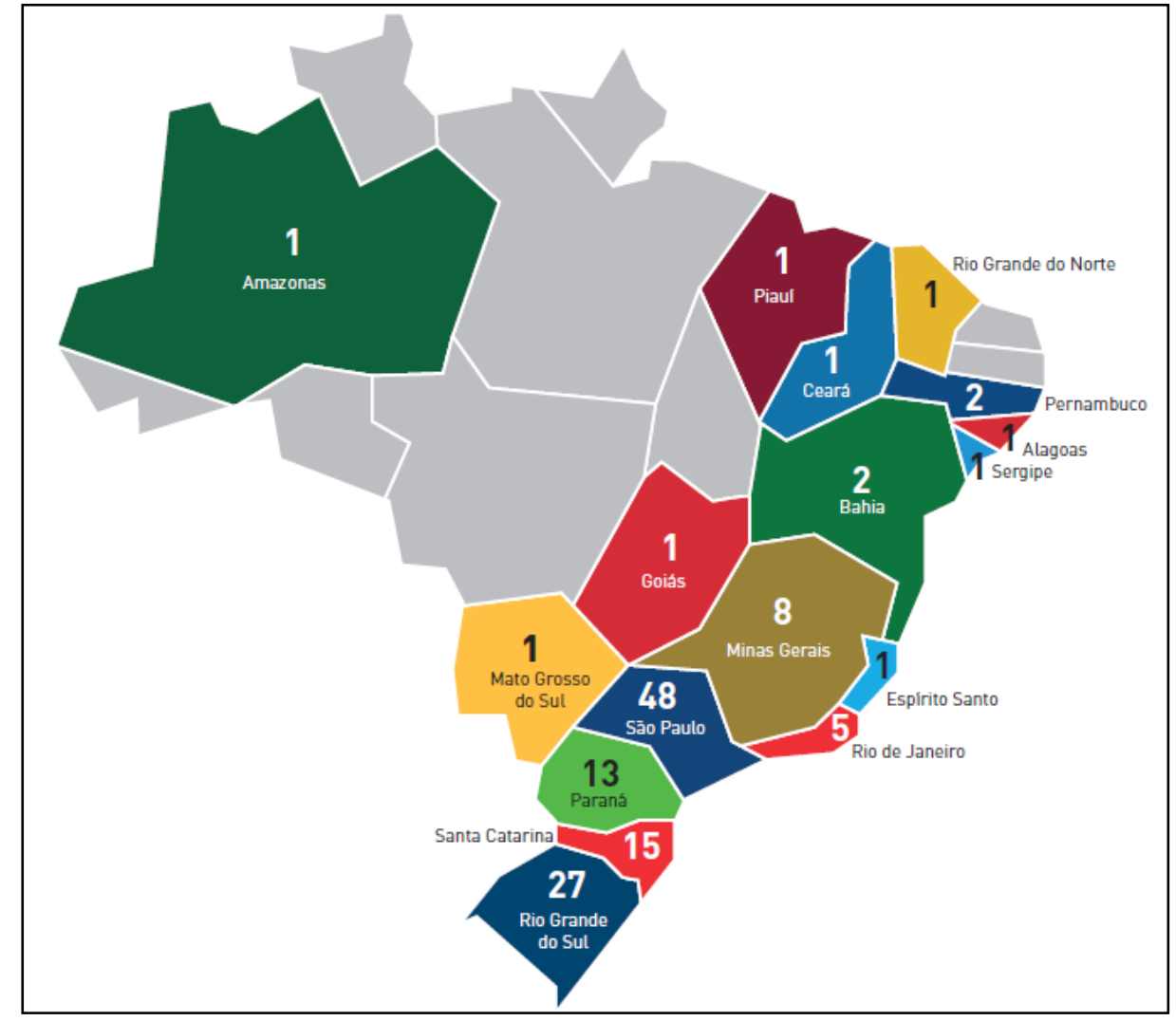

Fonte: ANFIR (2018)

A empresa em questão conta com uma vasta linha de implementos, que atende diversos segmentos de transporte e várias regiões do Brasil; todos os seus produtos são fabricados sob encomenda, sendo os principais: carroceria metálica, poli guindaste, báscula truck, báscula toco, báscula abertura lateral, furgão corrugado, carroceria de madeira, carroceria florestal, cabine suplementar, carroceria sobre-grade, carroceria em duralumínio, carroceria metálica de distribuição de gás e água, plataforma auto socorro, prancha carrega tudo, linha viva, torre de escada giratória, instalações de guindastes, alongamentos de entre-eixos e modificação de carrocerias. Martins e Laugeni 
(2005) definem que manufatura sob encomenda é o processo onde o produto e as suas partes são produzidas a partir do momento que o cliente realiza o pedido.

Para exemplificar a implementação do MRP escolheu-se três produtos de maior demanda da empresa, através de seus relatórios de vendas dos últimos 12 meses, sendo esses o furgão corrugado, a cabine suplementar, e a plataforma auto socorro. Maiores detalhes sobre esses produtos são dados a seguir.

Furgão corrugado série 1000: Fabricado principalmente em alumínio (FIGURA 3), caracteriza-se pela versatilidade de aplicação, sendo utilizado no transporte de carga seca em geral (mercadorias paletizadas ou encaixotadas, peças, sacários, tonéis, engradados e outros) e diversas cargas secas que precisam ser protegidas do sol e calor ambiente. Possui carroceria única, composta por compartimento de carga separado do habitáculo dos ocupantes por um painel divisório sendo o acesso ao compartimento de carga feito por porta lateral e/ou traseira.

Figura 3: furgão corrugado série 1000

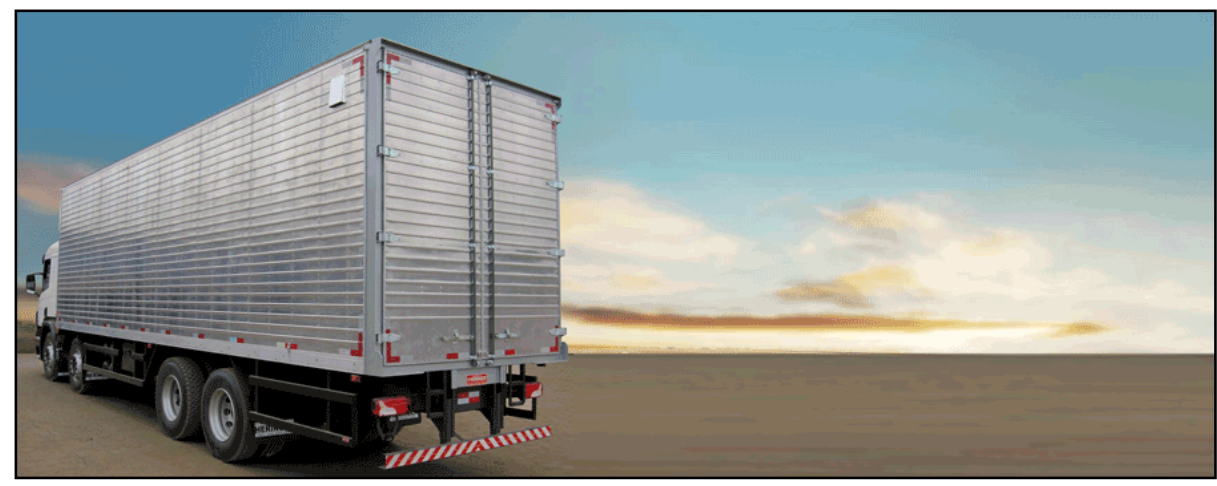

Fonte: Imagem cedida pela empresa.

Cabine suplementar para 4 pessoas: equipamento veicular destinado ao transporte de passageiros, separada da cabine do veículo sua ocupação, incluindo a lotação do veículo original, e de até nove ocupantes, conforme ilustrado na Figura 4.

Figura 4: cabine suplementar

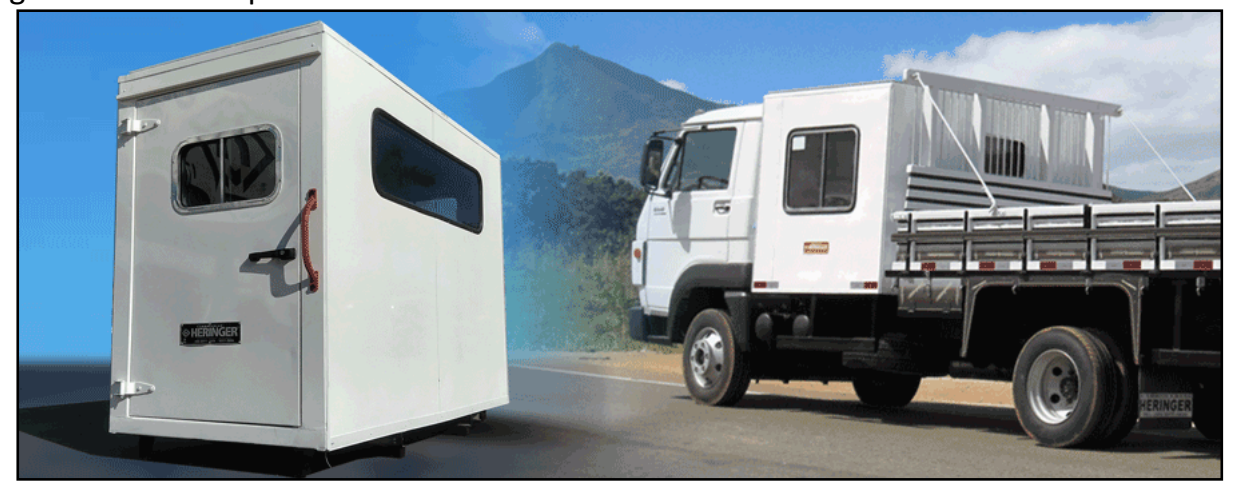

Fonte: Imagem cedida pela empresa. 
Plataforma auto socorro: A plataforma auto socorro é um implemento onde os automóveis são colocados, ela movimenta de maneira específica para formar uma rampa, que possibilita aos veículos de subir na plataforma, e é considerada um componente de alta capacidade de transporte de veículos. Seu sistema hidráulico de alto desempenho possibilita o transporte de veículos de maneira prática e segura, agilizando os procedimentos de remoção e racionalizando a totalidade do processo de socorro a automóveis danificados, conforme ilustrado na Figura 5.

Figura 5: plataforma auto socorro

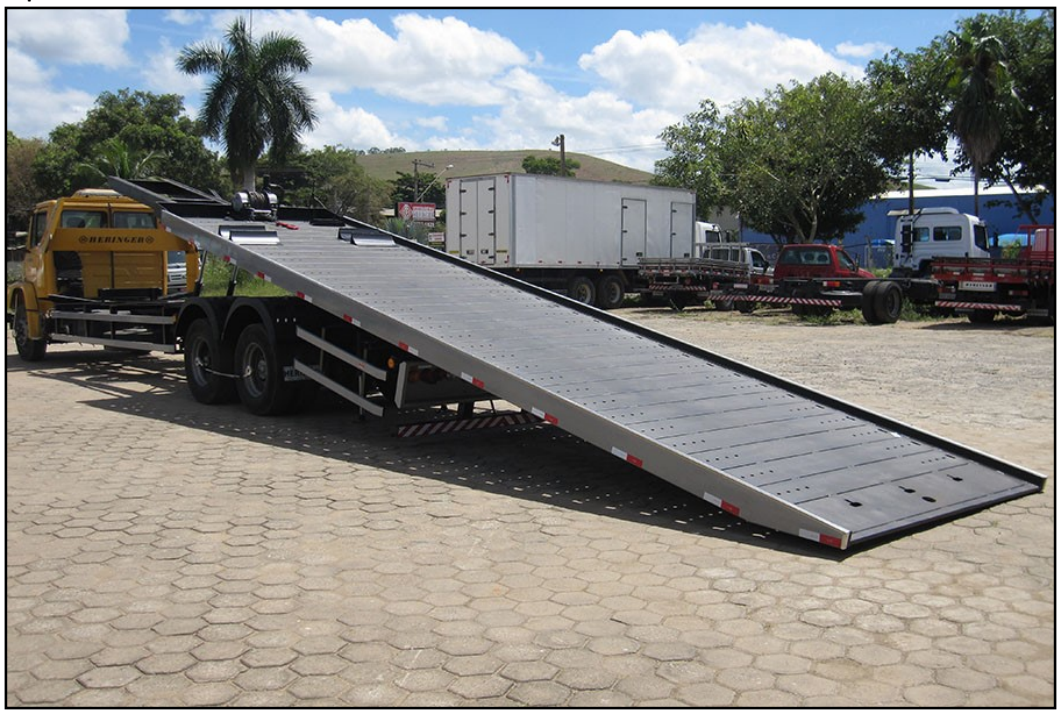

Fonte: Imagem cedida pela empresa.

Atualmente a empresa não conta com um sistema que integra suas informações, também não possui um responsável que esteja envolvido unicamente com o gerenciamento de informações referentes ao PCP, O planejamento e feito de forma intuitiva e sem nenhum registro do que deve ser produzido ou comprado, se já existe matéria prima em estoque ou não, portanto alguns itens são percebidos sua falta na montagem final para entrega ao cliente, o que muitas vezes pode atrasar a entrega.

A lucratividade da empresa também e feita por estimativa uma vez que não há registros de custo de produção e matéria prima bem definidos.

Para a implementação do sistema proposto a empresa deverá treinar seus funcionários de vendas, compras, estoque e gestores e designar um funcionário para alimentação dos dados no sistema, para que ele funcione corretamente e traga os benefícios esperados para a empresa, os projetos estruturais também devem ser repensados e divididos em subníveis para maior facilidade de controle e fabricação dos implementos.

A seguir serão descritas as estruturas dos implementos selecionados, bem como a lista dos seus materiais e as características do sistema de gestão implementado, para a realização do estudo. Trata-se de um passo importante para o desenvolvimento do planejamento e controle da produção dos mesmos. 
O furgão corrugado (série 1000) possui como base das suas estruturas os seguintes itens: (i) pré-painel chapa e ômegas centrais $1250 \times 2380 \mathrm{~mm}$; (ii) prépainel chapa e ômegas; (iii) painel lateral esquerdo; (iv) conjunto quadro traseira; (v) teto $6542 \times 2600 \mathrm{~mm}$; (vi) porta traseira $2600 \times 2536 \mathrm{~mm}$. A árvore do produto encontra-se apresentada na Figura 7.

Figura 7: estrutura em árvore do implemento furgão corrugado série 1000

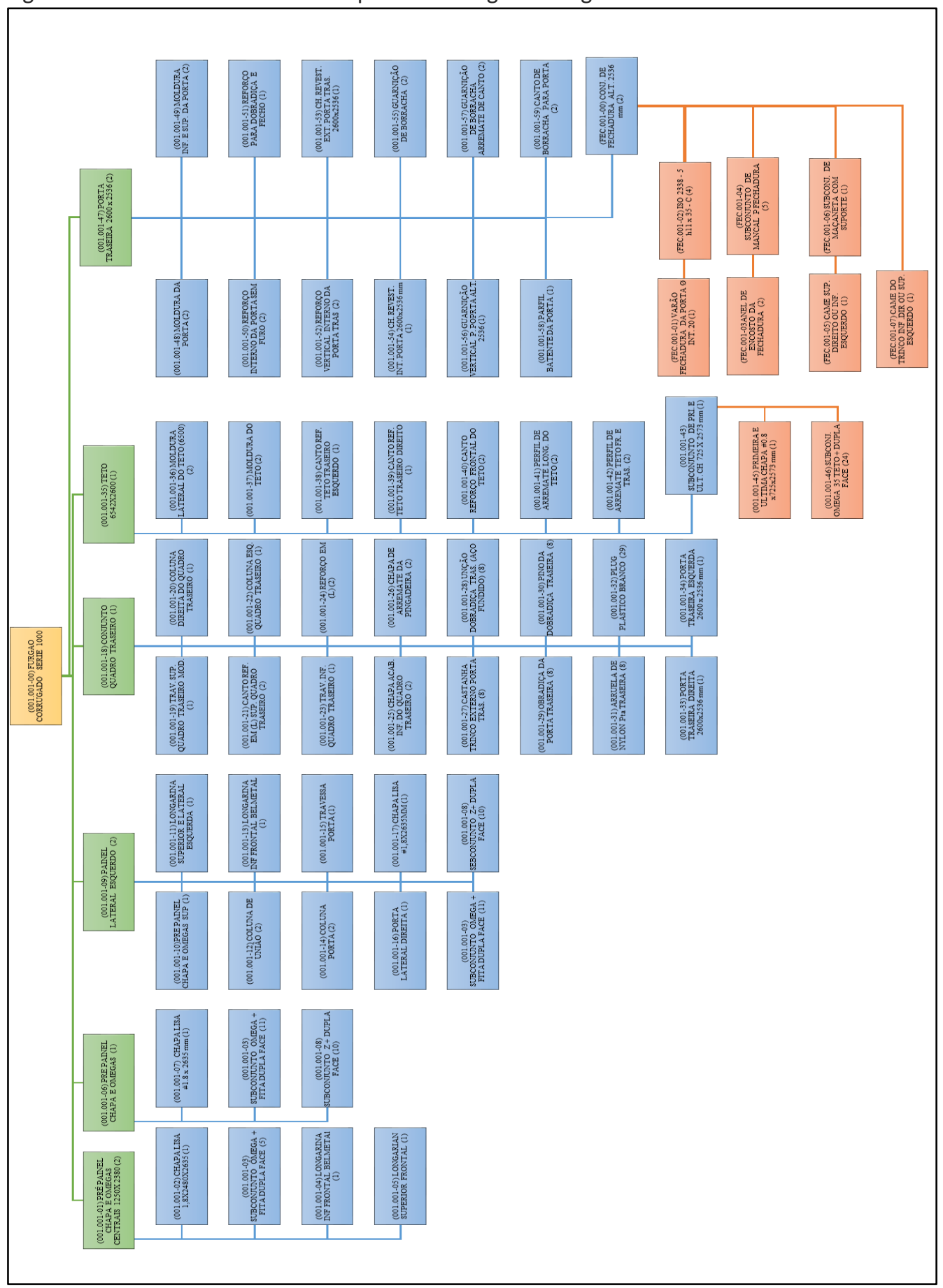


A Figura 8 mostra, de maneira tridimensional, como deve ficar a montagem final do produto. A ilustração foi cedida pela empresa, que disponibiliza o conteúdo aos responsáveis pela produção e montagem para facilitar a fabricação. No entanto, registra-se que a empresa não dispõe de manual de montagem dos itens.

Figura 8: Furgão corrugado

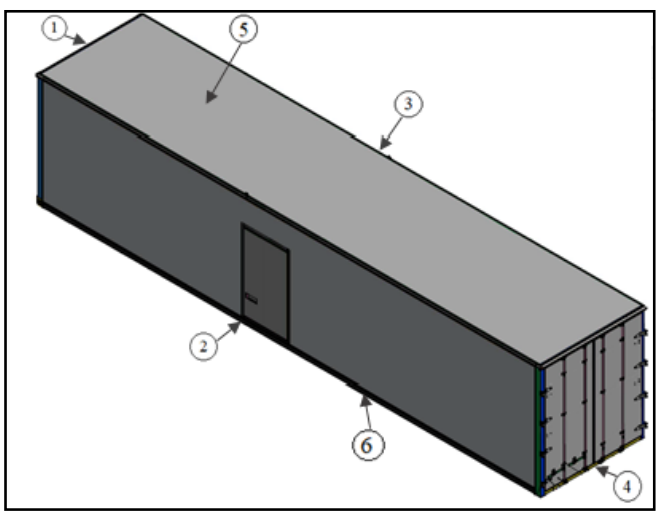

Fonte: Adaptado arquivo da empresa, cedido pela empresa em estudo.

Figura 9 - estrutura multinível do implemento furgão corrugado série 1000

\begin{tabular}{|c|c|c|c|c|c|c|c|c|c|c|}
\hline \multicolumn{11}{|c|}{ Estrutura de produto multinivel } \\
\hline \multicolumn{11}{|c|}{$\begin{array}{l}\text {-Filtros (clique para configurar: } \nabla \text { ) } \\
\text { (Ixibir os itens-filhos opcionais do grupo do item-pai }\end{array}$} \\
\hline \multirow[t]{2}{*}{ so } & Ocultar filtros (3) & 14 \& (1) 2250 (1) & & & & & & & & Exibindo itens 1 - 50 de 97 \\
\hline & Item & Descrị̧̃o & Qt & Unid & Procedência & Peso un $(\mathrm{kg})$ & Peso tot $(\mathrm{kg})$ & Ind perda & Cst un $(R \$)$ & Cst tot (R\$) \\
\hline 믄 & $001.001-00$ & FURGÃO CORRUGADO & 1,00 & un & Fabricado & 0,000 & 0,000 & 0 & 0,00 & 0,00 \\
\hline$\square$ & $+001.001-01$ & +PRÉ PAINEL CHAPA E & 2,00 & PC & Fabricado & 0,000 & 0,000 & 1 & 0,00 & 0,00 \\
\hline$\square$ & $++001.001-02$ & ++ CHAPA LISA $1,8 \times 24 \ldots$ & 2,00 & PC & Fabricado & 0,000 & 0,000 & 1 & 0,00 & 0,00 \\
\hline$\square$ & +++ CHA.007-00 & +++ CHAPA $141200 \times 3 .$. & 61,55782 & $\mathrm{~kg}$ & Comprado & $0,000 \not$ & 0,000 & 1 & $0,00 \not$ & 0,00 \\
\hline$\square$ & $++001.001-03$ & ++SUBCONJUNTO ÔME... & 10,00 & PC & Comprado & $0,000 \not$ & 0,000 & 1 & 0,004 & 0,00 \\
\hline$\square$ & $++001.001-04$ & ++LONGARINA INF FR. & 2,00 & PC & Comprado & $0,000 \not$ & 0,000 & 1 & 0,004 & 0,00 \\
\hline$\square$ & $++001.001-05$ & ++ LONGARIAN SUPERI. & 2,00 & PC & Comprado & $0,000 \not$ & 0,000 & 1 & $0,00 \not$ & 0,00 \\
\hline$\square$ & $+001.001-06$ & +PRE PAINEL CHAPA E & 1,00 & PC & Fabricado & 0,000 & 0,000 & 1 & $0,00 \not$ & 0,00 \\
\hline$\square$ & $++001.001-07$ & ++ CHAPA LISA $\equiv 1.8 \times \ldots$ & 1,00 & PC & Fabricado & 0,000 & 0,000 & 1 & $0,00 \not$ & 0,00 \\
\hline$\square$ & +++ CHA. $007-00$ & +++ CHAPA $141200 \times 3$. & 30,77891 & $\mathrm{~kg}$ & Comprado & $0,000 \not$ & 0,000 & 1 & $0,00 \not$ & 0,00 \\
\hline$\square$ & $++001.001-03$ & ++SUBCONJUNTO ÔME. & 11,00 & PC & Comprado & 0,000 & 0,000 & 1 & $0,00 \&$ & 0,00 \\
\hline$\square$ & $++001.001-08$ & ++SUBCONJUNTO $Z+\ldots$ & 10,00 & PC & Comprado & $0,000 \not$ & 0,000 & 1 & $0,00 \not$ & 0,00 \\
\hline$\square$ & $+001.001-09$ & +PAINEL LATERAL ESQ & 2,00 & PC & Fabricado & 0,000 & 0,000 & 1 & $0,00 \not$ & 0,00 \\
\hline$\square$ & $++001.001-10$ & ++PRE PAINEL CHAPA & 2,00 & PC & Fabricado & 0,000 & 0,000 & 1 & $0,00 \not$ & 0,00 \\
\hline$\square$ & +++ CHA.007-00 & +++ CHAPA $141200 \times 3 .$. & 20,60 & $\mathrm{~kg}$ & Comprado & $0,000 \not$ & 0,000 & 1 & $0,00 \not$ & 0,00 \\
\hline$\square$ & $++001.001-11$ & ++ +LONGARINA SUPERI. & 2,00 & PC & Comprado & $0,000 \not$ & 0,000 & 1 & $0,00 \not$ & 0,00 \\
\hline$\square$ & $++001.001-12$ & ++COLUNA DE UNIÂOO & 4,00 & PC & Fabricado & 0,000 & 0,000 & 1 & $0,00 \not$ & 0,00 \\
\hline$\square$ & +++ CHA. $008-00$ & +++ CHAPA $201200 \times 3 .$. & 74,5178 & $\mathrm{~kg}$ & Comprado & $0,000 \not$ & 0,000 & 1 & $0,00 \not$ & 0,00 \\
\hline$\square$ & $++001.001-13$ & ++LONGARINA INF FR. & 2,00 & PC & Comprado & $0,000 \not$ & 0,000 & 1 & $0,00 \not$ & 0,00 \\
\hline$\square$ & $++001.001-14$ & ++COLUNA PORTA & 4,00 & PC & Comprado & $0,000 \not$ & 0,000 & 1 & $0,00 \gg$ & 0,00 \\
\hline$\square$ & $++001.001-15$ & ++ TRAVESSA PORTA & 2,00 & PC & Comprado & $0,000 \not$ & 0,000 & 1 & $0,00 \not$ & 0,00 \\
\hline$\square$ & $++001.001-16$ & ++PORTA LATERAL DIR. & 2,00 & PC & Comprado & $0,000 \not$ & 0,000 & 1 & $0,00 \not$ & 0,00 \\
\hline$\square$ & $++001.001-17$ & ++ CHAPA LISA $=1,8 \times 2 \ldots$ & 2,00 & PC & Fabricado & 0,000 & 0,000 & 1 & $0,00 \not$ & 0,00 \\
\hline$\square$ & +++ CHA, $007-00$ & +++CHAPA $141200 \times 3 .$. & 24,8217 & $\mathrm{~kg}$ & Comprado & $0,000 \not$ & 0,000 & 1 & $0,00 \not$ & 0,00 \\
\hline$\square$ & $++001.001-03$ & ++SUBCONJUNTO ÔME. & 22,00 & PC & Comprado & $0,000 \not$ & 0,000 & 1 & 0,004 & 0,00 \\
\hline$\square$ & $++001.001-08$ & ++ SUBCONJUNTO $Z+$ & 20,00 & PC & Comprado & $0,000 \not$ & 0,000 & 1 & $0,00 \$$ & 0,00 \\
\hline$\square$ & $+001.001-18$ & +CONJUNTO QUADRO & 1,00 & PC & Fabricado & 0,000 & 0,000 & 1 & $0,00 \not$ & 0,00 \\
\hline$\square$ & $++001.001-19$ & ++TRAV. SUP. QUADRO. & 1,00 & PC & Comprado & $0,000 \not$ & 0,000 & 1 & $0,00 \gg$ & 0,00 \\
\hline$\square$ & $++001.001-20$ & ++ COLUNA DIREITA D... & 1,00 & PC & Fabricado & 0,000 & 0,000 & 1 & $0,00 \not$ & 0,00 \\
\hline$\square$ & +++ CHA.001-01 & +++ CHAPA $121200 \times 3 \ldots$ & 10,20 & kg & Comprado & $0,000 \not$ & 0,000 & 1 & $0,00 \bowtie$ & 0,00 \\
\hline$\square$ & $++001.001-21$ & ++CANTO REF. EM (L) .. & 2,00 & PC & Fabricado & 0,000 & 0,000 & 1 & $0,00 \not$ & 0,00 \\
\hline$\square$ & +++PFL.001-01 & +++PERFIL L 50X50×3.. & 8,00 & $\mathrm{~kg}$ & Comprado & $0,000 \not$ & 0,000 & 1 & $0,00 \not$ & 0,00 \\
\hline$\square$ & $++001.001-22$ & ++COLUNA ESQ. QUA... & 1,00 & PC & Fabricado & 0,000 & 0,000 & 1 & $0,00 \not$ & 0,00 \\
\hline$\square$ & +++ CHA.001-01 & +++ CHAPA $121200 \times 3 .$. & 5,35 & $\mathrm{~kg}$ & Comprado & $0,000 \not$ & 0,000 & 1 & $0,00 \not$ & 0,00 \\
\hline$\square$ & $++001.001-23$ & ++TRAV. INF. QUADRO.. & 1,00 & PC & Comprado & $0,000 \not$ & 0,000 & 1 & $0,00 \not$ & 0,00 \\
\hline$\square$ & $++001.001-24$ & ++REFORÇO EM (L) & 2,00 & PC & Fabricado & 0,000 & 0,000 & 1 & $0,00 \not$ & 0,00 \\
\hline$\square$ & +++PFL.001-01 & +++PERFIL L 50X50X3. & 12,36 & $\mathrm{~kg}$ & Comprado & $0,000 \not$ & 0,000 & 1 & $0,00 \not$ & 0,00 \\
\hline$\square$ & $++001.001-25$ & ++ CHAPA ACAB. INF. D & 2,00 & PC & Fabricado & 0,000 & 0,000 & 1 & $0,00 \not$ & 0,00 \\
\hline$\square$ & $+++\mathrm{CHA}, 001-01$ & +++ CHAPA $121200 \times 3 .$. & 16,65 & $\mathrm{~kg}$ & Comprado & $0,000 \not$ & 0,000 & 1 & $0,00 \not$ & 0,00 \\
\hline$\square$ & $++001.001-26$ & ++CHAPA DE ARREMAT. & 2,00 & PC & Fabricado & 0,000 & 0,000 & 1 & $0,00 \not$ & 0,00 \\
\hline$\square$ & +++CHA.007-00 & +++ CHAPA $141200 \times 3 .$. & 31,80 & $\mathrm{~kg}$ & Comprado & $0,000 \not$ & 0,000 & 1 & $0,00 \not$ & 0,00 \\
\hline$\square$ & $++001.001-27$ & ++CASTANHA TRINCO ... & 8,00 & PC & Comprado & $0,000 \gg$ & 0,000 & 1 & $0,00 \not$ & 0,00 \\
\hline$\square$ & $++001.001-28$ & ++JUNÇ̃̃o DOBRADIÇ... & 8,00 & PC & Comprado & $0,000 \not$ & 0,000 & 1 & $0,00 \not$ & 0,00 \\
\hline$\square$ & $++001.001-29$ & ++DOBRADIÇA DA PO... & 8,00 & PC & Comprado & $0,000 \not$ & 0,000 & 1 & $0,00 \not$ & 0,00 \\
\hline$\square$ & $++001.001-30$ & ++PINO DA DOBRADIC.... & 8,00 & PC & Comprado & $0,000 \not$ & 0,000 & 1 & $0,00 \not$ & 0,00 \\
\hline$\square$ & $++001.001-31$ & ++ARRUELA DE NYLON... & 8,00 & PC & Comprado & $0,000 \not$ & 0,000 & 1 & $0,00 \gg$ & 0,00 \\
\hline$\square$ & $++001.001-32$ & ++PLUG PLASTICO BR. & 29,00 & $\mathrm{PC}$ & Comprado & 0,000 & 0,000 & 1 & $0,00 \not$ & 0,00 \\
\hline$\square$ & $++001.001-33$ & ++PORTA TRASEIRA DI. & 1,00 & PC & Comprado & $0,000 \not$ & 0,000 & 1 & $0,00 \not$ & 0,00 \\
\hline$\square$ & $++001.001-34$ & ++PORTA TRASEIRA E... & 1,00 & PC & Comprado & $0,000 \not$ & 0,000 & 1 & $0,00 \not$ & 0,00 \\
\hline$\square$ & $+001.001-35$ & +TETO $6542 \times 2600$ & 1,00 & PC & Fabricado & 0,000 & 0,000 & 1 & $0,00 \gg$ & 0,00 \\
\hline
\end{tabular}

Fonte: Sistema MAXIPROD. Autoria própria. 
Ao todo, são necessárias 71 peças distintas para a produção do furgão corrugado. As principais matérias-primas utilizadas são as chapas de aço e borracha para as vedações.

Para o registro dos itens no sistema, primeiro foram montados os subconjuntos, para facilitar o cadastro em pacotes menores, com informações mais organizadas - Figura 9. Depois, esses dados foram inseridos manualmente no sistema - ou por planilhas do software Microsoft office Excel (MS Excel) fornecidas no próprio sistema MAXIPROD ${ }^{\circledR}$, ou através do software de projetos 3D. Cabe ao operador identificar a ação que implique em maior eficiência no cadastro dos itens.

A organização da estrutura do produto apresentada em subníveis propicia melhor compreensão por parte dos montadores e também no controle da produção, já que o produto e dividido em pequenas partes.

\section{Cabine Suplementar 4 Pessoas}

Figura 10: estrutura em arvore do implemento cabine suplementar 4 pessoas

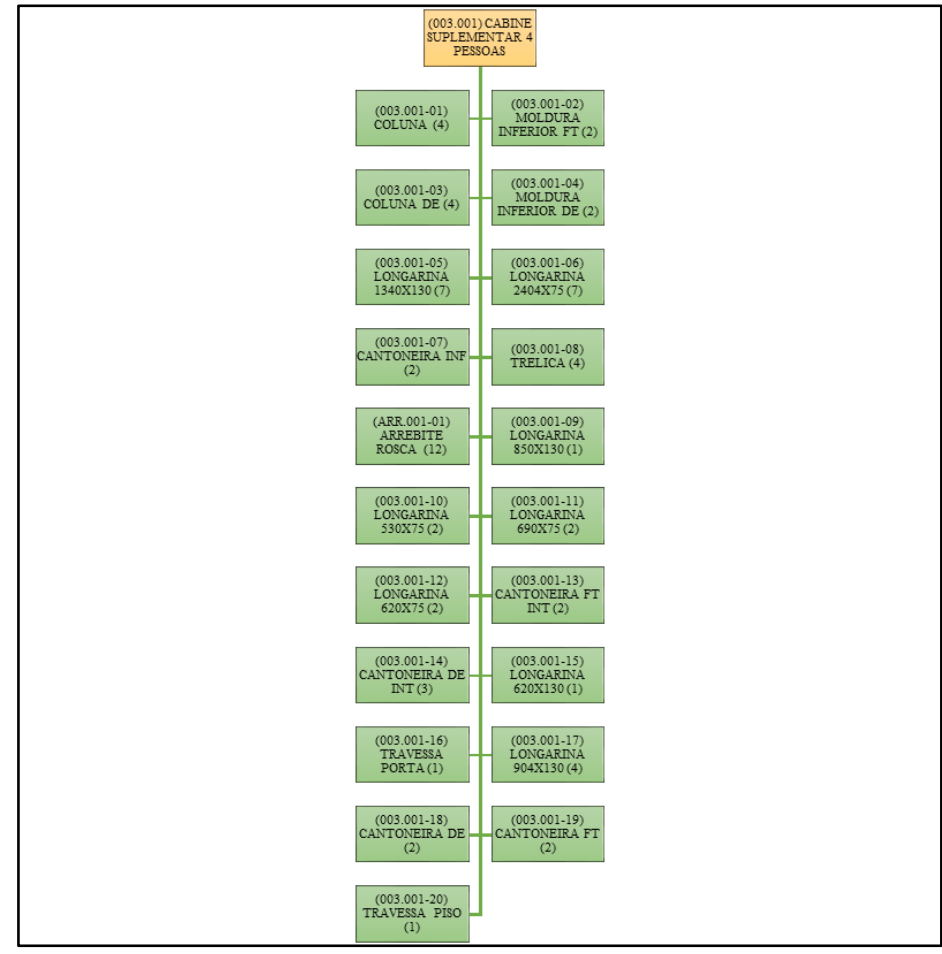

Fonte: Autoria própria.

Como a cabine suplementar possui poucos itens, optou-se por não subdividila, sendo cadastrados apenas os seus itens: (i) coluna; (ii) moldura inferior ft; (iii) coluna de; (iv) moldura inferior direito; (v) longarina 1340x130mm; (vi) longarina $2404 \times 75 \mathrm{~mm}$; (vii) cantoneira inferior; (viii) treliça; (ix) arrebite rosca; (x) longarina 850x130mm; (xi) longarina 530x75mm; (xii) longarina 690x75mm;(xii)longarina 620x75; (xiv) cantoneira interna; (xv) cantoneira direita interna; (xvi) longarina 620x130mm; (xvii) travessa porta; (xviii) longarina 904x130mm; (xix) cantoneira direita; (xx) cantoneira esquerda; (xxi) travessa piso. Ao todo são 21 itens 
distintos com suas respectivas quantidades que pode ser visualizado na arvore do produto que se encontra representada na Figura 10.

Figura 11: projeto cabine suplementar 4 pessoas

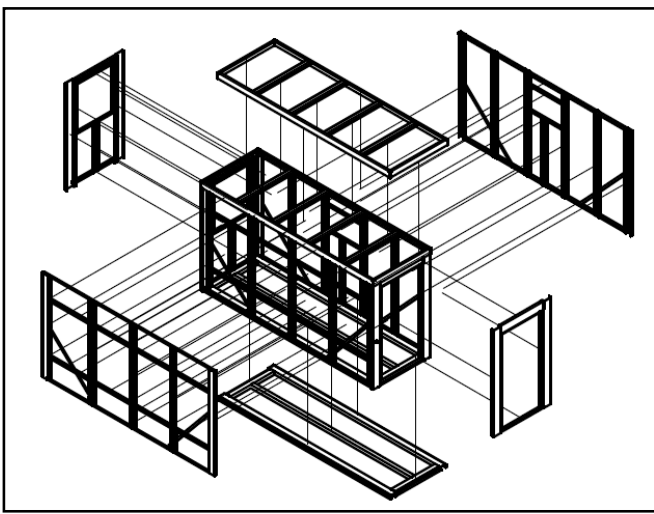

Fonte: Adaptado arquivo da empresa, cedido pela empresa em estudo.

A Figura 11 mostra a cabine suplementar com suas vistas "explodidas", demonstrando do que é composto cada lado da cabine. A ilustração também foi cedida pela empresa, que disponibiliza o conteúdo aos responsáveis pela produção e montagem de modo a facilitar o processo de fabricação.

Figura 12: Estrutura multinível do implemento cabine suplementar 4 pessoas

\begin{tabular}{|c|c|c|c|c|c|c|c|c|c|c|}
\hline \multicolumn{11}{|c|}{ Estrutura de produto multinivel } \\
\hline \multicolumn{11}{|c|}{$\begin{array}{l}\text {-Filtros (clique para configurar: } \nabla \text { ) } \\
\square \text { Exibir os itens-filhos opcionais do grupo do item-pai }\end{array}$} \\
\hline \multirow[t]{2}{*}{ ss } & Ocultar filtros (2) & P 14 (1) 50 - M & & & & & & & & Exibindo itens 1 - 42 de 42 \\
\hline & Item & Descrição & Qt & Unid & Procedência & Peso un $(\mathrm{kg})$ & Peso tot $(\mathrm{kg})$ & Ind perda & & Cst tot $(R \$)$ \\
\hline 믈 & $003.001-00$ & CABINE SUPLEMENTAR. & 1,00 & un & Fabricado & 0,000 & 0,000 & 0 & 0,00 & 0,00 \\
\hline$\square$ & $+003.001-01$ & +COLUNA & 4,00 & PC & Fabricado & 0,000 & 0,000 & 1 & 0,00 & 0,00 \\
\hline$\square$ & ++ CHA.001-01 & ++CHAPA $121200 \times 3000$ & 21,11616 & $\mathrm{~kg}$ & Comprado & 0,000 & 0,000 & 1 & $0,00 \not$ & 0,00 \\
\hline$\square$ & $+003.001-02$ & +MOLDURA INFERIOR FT & 1,00 & PC & Fabricado & 0,000 & 0,000 & 1 & 0,00 & 0,00 \\
\hline$\square$ & ++ CHA.001-01 & ++CHAPA $121200 \times 3000$ & 11,1384 & $\mathrm{~kg}$ & Comprado & 0,000 & 0,000 & 1 & $0,00 \not$ & 0,00 \\
\hline$\square$ & $+003.001-03$ & +COLUNA DE & 4,00 & PC & Fabricado & 0,000 & 0,000 & 1 & 0,00 & 0,00 \\
\hline$\square$ & ++ CHA.001-01 & ++CHAPA $121200 \times 3000$ & 21,11616 & $\mathrm{~kg}$ & Comprado & 0,000 & 0,000 & 1 & $0,00 \not$ & 0,00 \\
\hline$\square$ & $+003.001-04$ & + MOLDURA INFERIOR ... & 2,00 & PC & Fabricado & 0,000 & 0,000 & 1 & 0,00 & 0,00 \\
\hline$\square$ & ++ CHA.001-01 & ++ CHAPA $121200 \times 3000$ & 5,824 & $\mathrm{~kg}$ & Comprado & 0,000 & 0,000 & 1 & 0,00 & 0,00 \\
\hline$\square$ & $+003.001-05$ & +LONGARINA $1340 \times 1$ & 7,00 & PC & Fabricado & 0,000 & 0,000 & 1 & 0,00 & 0,00 \\
\hline$\square$ & ++ CHA. $003-00$ & ++ CHAPA $1 / 4^{\prime \prime} 1200 \times 3 . .$. & 60,78709 & $\mathrm{~kg}$ & Comprado & 0,000 & 0,000 & 1 & $0,00 \not$ & 0,00 \\
\hline$\square$ & $+003.001-06$ & + LONGARINA $2404 \times 75$ & 2,00 & $\mathrm{PC}$ & Fabricado & 0,000 & 0,000 & 1 & 0,00 & 0,00 \\
\hline$\square$ & ++ CHA. $003-00$ & ++ CHAPA $1 / 4^{\prime \prime} 1200 \times 3 .$. & 17,97592 & $\mathrm{~kg}$ & Comprado & 0,000 & 0,000 & 1 & $0,00 \not$ & 0,00 \\
\hline$\square$ & $+003.001-07$ & +CANTONEIRA INF & 2,00 & $\mathrm{PC}$ & Fabricado & 0,000 & 0,000 & 1 & 0,00 & 0,00 \\
\hline$\square$ & ++ CHA.001-01 & ++CHAPA $121200 \times 3000$ & 5,00032 & $\mathrm{~kg}$ & Comprado & 0,000 & 0,000 & 1 & $0,00 \not$ & 0,00 \\
\hline$\square$ & $+003.001-08$ & +TRELIÇA & 4,00 & $\mathrm{PC}$ & Fabricado & 0,000 & 0,000 & 1 & 0,00 & 0,00 \\
\hline$\square$ & ++ CHA.001-01 & ++ CHAPA $121200 \times 3000$ & 2,08 & $\mathrm{~kg}$ & Comprado & 0,000 & 0,000 & 1 & $0,00 \not$ & 0,00 \\
\hline 至 & $+003.001-09$ & + LONGARINA $850 \times 130$ & 1,00 & PC & Fabricado & 0,000 & 0,000 & 1 & 0,00 & 0,00 \\
\hline$\square$ & $++\mathrm{CHA} .001-01$ & ++ CHAPA $121200 \times 3000$ & 2,2984 & $\mathrm{~kg}$ & Comprado & 0,000 & 0,000 & 1 & $0,00 \not$ & 0,00 \\
\hline 散 & $+003.001-10$ & +LONGARINA $530 \times 75$ & 2,00 & PC & Fabricado & 0,000 & 0,000 & 1 & 0,00 & 0,00 \\
\hline$\square$ & ++ CHA.001-01 & ++ CHAPA $121200 \times 3000$ & 1,6536 & $\mathrm{~kg}$ & Comprado & 0,000 & 0,000 & 1 & 0,00 & 0,00 \\
\hline$\square$ & $+003.001-11$ & +LONGARINA $690 \times 75$ & 2,00 & PC & Fabricado & 0,000 & 0,000 & 1 & 0,00 & 0,00 \\
\hline$\square$ & $++\mathrm{CHA} .001-01$ & ++ CHAPA $121200 \times 3000$ & 2,69818 & $\mathrm{~kg}$ & Comprado & 0,000 & 0,000 & 1 & $0,00 \not$ & 0,00 \\
\hline$\square$ & $+003.001-17$ & +LONGARINA $904 \times 130$ & 4,00 & PC & Fabricado & 0,000 & 0,000 & 1 & 0,00 & 0,00 \\
\hline$\square$ & ++ CHA.001-01 & ++CHAPA $121200 \times 3000$ & 9,77768 & $\mathrm{~kg}$ & Comprado & 0,000 & 0,000 & 1 & $0,00 \not$ & 0,00 \\
\hline$\square$ & $+003.001-18$ & +CANTONEIRA DE & 2,00 & PC & Fabricado & 0,000 & 0,000 & 1 & 0,00 & 0,00 \\
\hline$\square$ & ++ CHA.004-01 & ++ CHAPA $161200 \times 3000$ & 2,06136 & $\mathrm{~kg}$ & Comprado & $0,000 \approx$ & 0,000 & 1 & $0,00 \not$ & 0,00 \\
\hline$\square$ & $+003.001-19$ & +CANTONEIRA FT & 2,00 & PC & Fabricado & 0,000 & 0,000 & 1 & 0,00 & 0,00 \\
\hline 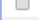 & ++ CHA.004-01 & ++ CHAPA $161200 \times 3000$ & 51,689 & kg & Comprado & 0,000 & 0,000 & 1 & $0,00 \nless$ & 0,00 \\
\hline$\square$ & $+003.001-20$ & +TRAVESSA PISO & 1,00 & PC & Fabricado & 0,000 & 0,000 & 1 & 0,00 & 0,00 \\
\hline$\square$ & ++ CHA. $003-00$ & ++ CHAPA $1 / 4^{\prime \prime} 1200 \times 3 .$. & 17,79645 & $\mathrm{~kg}$ & Comprado & $0,000 \not$ & 0,000 & 1 & $0,00 \not$ & 0,00 \\
\hline 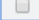 & +ARR.001-01 & +ARREBITE ROSCA & 12,00 & un & Comprado & 0,000 \& & 0,000 & 1 & $0,00 \approx$ & 0,00 \\
\hline
\end{tabular}

Fonte: Sistema MAXIPROD. Autoria própria.

Para o cadastro do implemento cabine suplementar 4 pessoas, foram adotados os mesmos procedimentos utilizados para o cadastro do furgão 
corrugado, diferenciando apenas os subníveis que este não apresenta, como pode ser observado na Figura 12.

Para produtos que não apresentam uma grande variedade de peças, pode-se optar por fazer o cadastro sem a necessidade de dividi-lo em partes menores, ficando a critério do responsável pelo cadastro dos itens.

\section{Plataforma Auto Socorro 4.5t}

A plataforma auto socorro 4.5t é composta pelos principais itens: (i) chassi fixo; (ii) chassi basculante; (iii) prancha móvel assoalho; (iv) prancha móvel. A sua estrutura do tipo árvore encontra-se na Figura 13.

Figura 13: estrutura em árvore do implemento plataforma auto socorro $4.5 t$

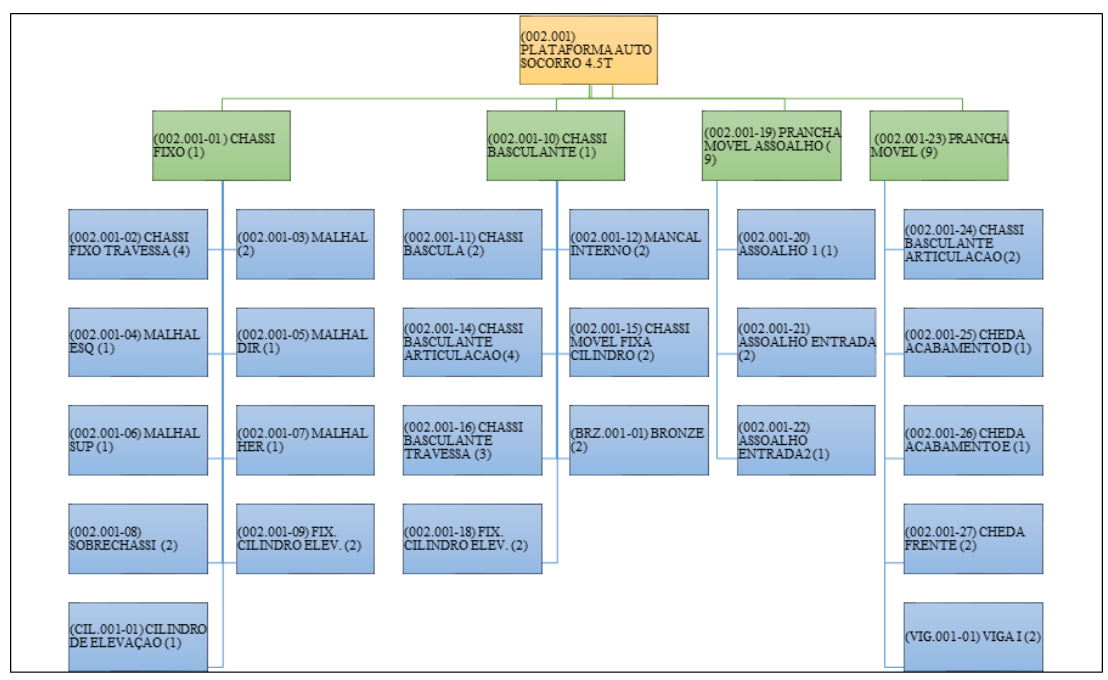

Fonte: Autoria própria.

$\mathrm{Na}$ Figura 14 encontra-se representada a estrutura de maneira tridimensional, simbolizando como fica a montagem final da plataforma que será inserida sobre o chassi do caminhão.

Figura 14: Plataforma auto socorro 4.5t

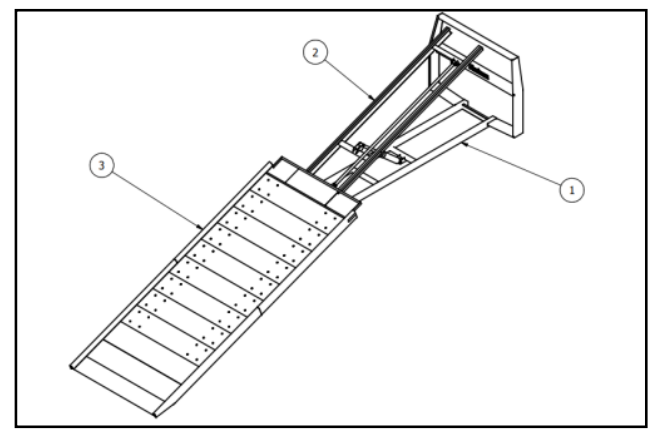

Fonte: Adaptado arquivo da empresa. 
Ao todo, são necessárias 29 modelos diferentes de peças para a composição da plataforma. As principais matérias-primas utilizadas são as chapas de aço, e borracha para as vedações, como na maior parte dos produtos da empresa.

A Figura 15 mostra a estrutura multinível do implemento "plataforma auto socorro", com as respectivas peças e quantidades para a fabricação do equipamento além de sua matéria-prima. Essas são algumas das informações cadastradas, mas o software também oferece opções para que o cadastro possa ficar mais completo, como cadastro de fornecedores de matéria-prima, se o item é fabricado ou comprado, entre outras.

Figura 15: estrutura multinível plataforma auto socorro $4.5 \mathrm{t}$

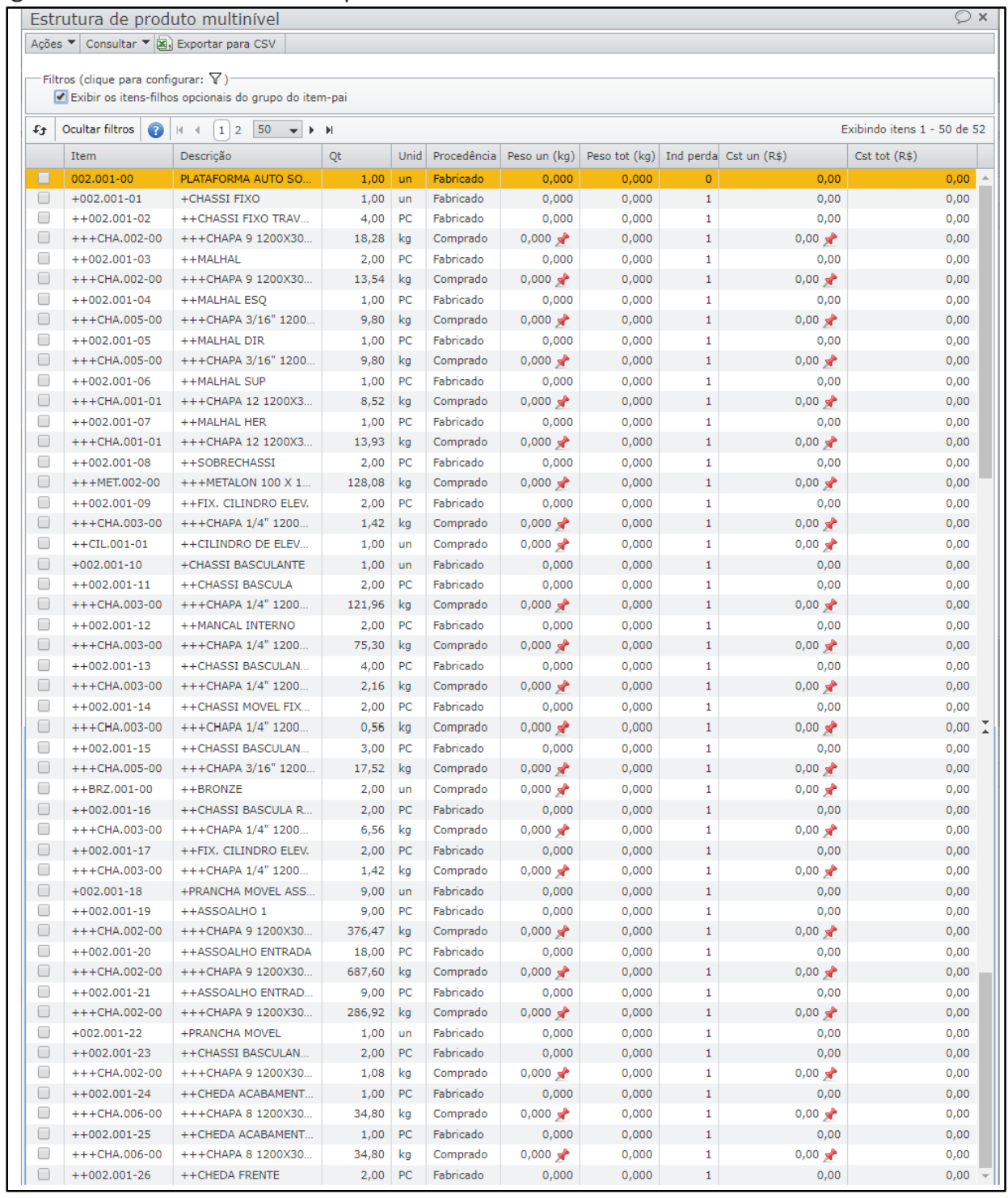

Fonte: Sistema MAXIPROD (2019)

O próximo tópico traz a exemplificação de uma ordem de produção gerada pelo sistema ERP MAXIPROD ${ }^{\circledR}$ e uma breve explanação a seu respeito. 


\section{Ordem de Produção}

Após o cadastro dos itens, e montadas as estruturas dos produtos, pode ser gerada ordens de produção como o exemplo a seguir (FIGURA 16). À medida em que se solicita a produção de uma dada quantidade de implementos, a cada pedido, também são geradas as quantidades de matérias-primas a serem baixadas do estoque, bem como de peças a serem produzidas ou compradas se essas não estiverem em estoque.

Figura 16: Ordem de produção da cabine suplementar 4 pessoas gerada pelo sistema MAXIPROD $^{\circledR}$

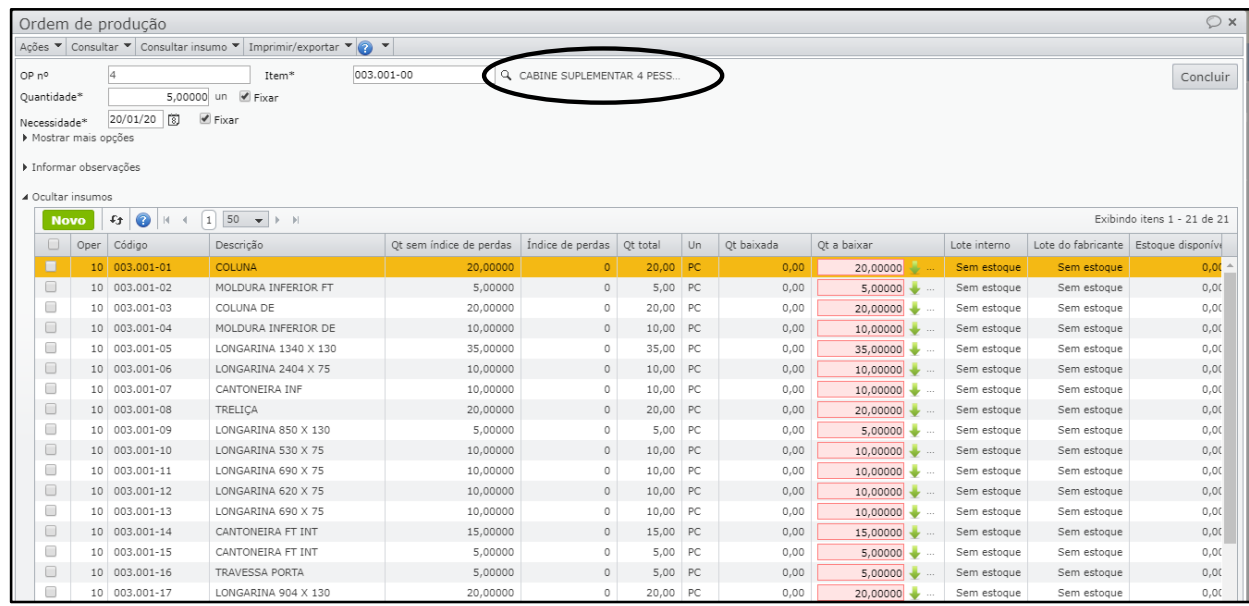

Fonte: Sistema MAXIPROD ${ }^{\circledR}(2019)$

Na Figura 17 a seguir, observa-se que somente o item arrebite rosca (ARR.001-01), contém estoque de 100 unidades. Logo, se for dada a baixa de 60 unidades para a produção de 5 cabines suplementares, restarão somente 40 unidades, já os outros itens devem ser comprados ou fabricados.

Figura 17: Ordem de produção da cabine suplementar 4 pessoas gerada pelo sistema MAXIPROD ${ }^{\circledR}$

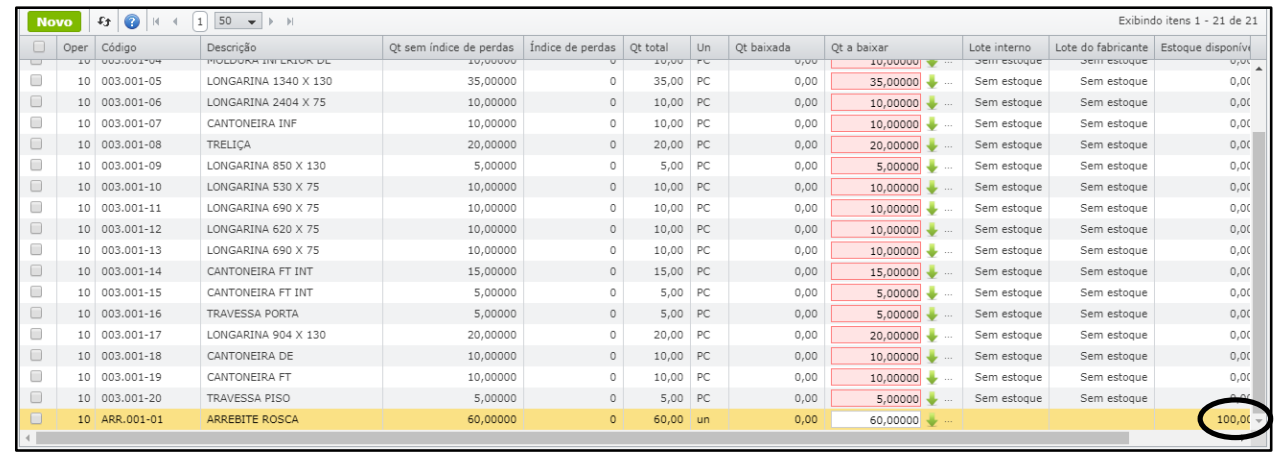

Fonte: Sistema MAXIPROD (2019)

A Figura 18 mostra a ordem de produção após a baixa das 60 unidades de arrebite rosca. Como exemplificado, em estoque restarão apenas 40 unidades 
desse item, pois as outras 60 unidades serão consumidas para a fabricação da cabine suplementar.

Figura 18: ordem de produção após baixa de estoque do item arrebite rosca

\begin{tabular}{|c|c|c|c|c|c|c|c|c|c|c|c|c|}
\hline \multicolumn{4}{|c|}{ 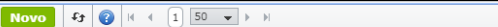 } & & & & & & & & \multicolumn{2}{|c|}{ Exibindo itens 1 - 21 de 21} \\
\hline$\square$ & Oper & 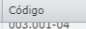 & 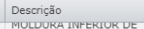 & Qt sem indice de perdas & Indice de perdas & Qt total & Un & Qt baixada & Qt a baixar & $\begin{array}{l}\text { Lote interno } \\
\text { semescouve }\end{array}$ & $\begin{array}{l}\text { Lote do fabricante } \\
\text { Sem estrove }\end{array}$ & Estoque disponive \\
\hline$\square$ & 10 & $003.001-05$ & LONGARINA $1340 \times 130$ & $\begin{array}{r}10,00000 \\
35,00000\end{array}$ & 0 & 35,00 & $\mathrm{PC}$ & $\begin{array}{l}0,00 \\
0,00\end{array}$ & \begin{tabular}{|c|}
10,000000 \\
35,000000 \\
\end{tabular} & $\begin{array}{l}\text { Sem essoque } \\
\text { Sem estoque }\end{array}$ & $\begin{array}{l}\text { Sem estroque } \\
\text { Sem estoque }\end{array}$ & $0,0 c^{\circ}$ \\
\hline$\square$ & 10 & $003.001-06$ & LONGARINA $2404 \times 75$ & 10,00000 & 0 & 10,00 & $\mathrm{PC}$ & 0,00 & 10,00000 & Sem estoque & Sem estoque & $0,0 \mathrm{c}$ \\
\hline$\square$ & 10 & $003.001-07$ & CANTONEIRA INF & 10,00000 & 。 & 10,00 & PC & 0,00 & 10,000000 & Sem estoque & Sem estoque & \\
\hline$\square$ & 10 & $003.001-08$ & TRELIC̣A & 20,00000 & 。 & 20,00 & PC & 0,00 & 20,00000 & Sem estoque & Sem estoque & 0,06 \\
\hline$\square$ & 10 & 003.001 .09 & LONGARRNA $850 \times 130$ & 5,00000 & 。 & 5,00 & PC & 0,00 & 5,00000 & Sem estoque & Sem estoque & 0,06 \\
\hline$\square$ & 10 & $003.001-10$ & LONGARINA $530 \times 75$ & 10,00000 & 0 & 10,00 & PC & 0,00 & 10,000000 & Sem estoque & Sem estoque & 0,06 \\
\hline$\square$ & 10 & $003.001-11$ & LONGARINA $690 \times 75$ & 10,00000 & 0 & 10,00 & PC & 0,00 & 10,00000 & Sem estoque & Sem estoque & $0,0 \mathrm{c}$ \\
\hline$\square$ & 10 & $003.001 \cdot 12$ & LONGARINA $620 \times 75$ & 10,00000 & 0 & 10,00 & PC & 0,00 & 10,000000 & Sem estoque & Sem estoque & $0,0<$ \\
\hline$\square$ & 10 & 003.001-13 & LONGARINA $690 \times 75$ & 10,00000 & 0 & 10,00 & PC & 0,00 & 10,00000 & Sem estoque & Sem estoque & 0,06 \\
\hline$\square$ & 10 & 003.001-14 & CANTONEIRA FT INT & 15,00000 & 0 & 15,00 & PC & 0,00 & 15,00000 & Sem estoque & Sem estoque & 0,00 \\
\hline$\square$ & 10 & $003.001-15$ & CANTONEIRA FT INT & 5,00000 & 0 & 5,00 & PC & 0,00 & 5,00000 & Sem estoque & Sem estoque & \\
\hline$\square$ & 10 & 003.001-16 & TRAVESSA PORTA & 5,00000 & $\circ$ & 5,00 & PC & 0,00 & 5,00000 & Sem estoque & Sem estoque & 0,0 \\
\hline$\square$ & 10 & 003.001-17 & LONGARINA $904 \times 130$ & 20,00000 & 。 & 20,00 & PC & 0,00 & 20,000000 & sem estoque & Sem estoque & \\
\hline$\square$ & 10 & $003.001 \cdot 18$ & CANTONEIRA DE & 10,00000 & 。 & 10,00 & PC & 0,00 & 10,000000 & Sem estoque & scm estoque & \\
\hline$\square$ & 10 & $003.001-19$ & CANTONEIRA FT & 10,00000 & $\circ$ & 10,00 & PC & 0,00 & 10,00000 & Sem estoque & Sem estoque & \\
\hline$\square$ & 10 & $003.001 \cdot 20$ & TRAVESSA PISO & 5,00000 & 0 & 5,00 & $\mathrm{PC}$ & 0,00 & 5,000000 & Sem estoaue & Sem estoave & \\
\hline 문 & 10 & ARR.001-01 & ARREBTTE ROSCA & 60,00000 & 0 & 60,00 & un & 60,00 & & & & 40,06 \\
\hline
\end{tabular}

Fonte: Sistema MAXIPROD (2019)

A seguir será apresentada a proposta de implementação do sistema ERP MAXPROD ${ }^{\circledR}$ na empresa.

\section{PROPOSTA DE IMPLEMENTAÇÃO DO MAXIPROD ${ }^{\circledR}$ NA EMPRESA}

Nos tópicos anteriores se demonstrou a importância da implementação do sistema de MRP I nos itens que registram maior venda em estudo. Isso porque possuem listas extensas de componentes de montagem e facilitam o planejamento e ordem de produção, segundo a disponibilidade e necessidade de ressuprimento de matérias-primas envolvidas no processo. A Figura 19 mostra o fluxograma com os passos da implementação do MRP I a partir do software MAXIPROD ${ }^{\circledR}$

Figura 7: passos para a implementacao do ERP na empresa

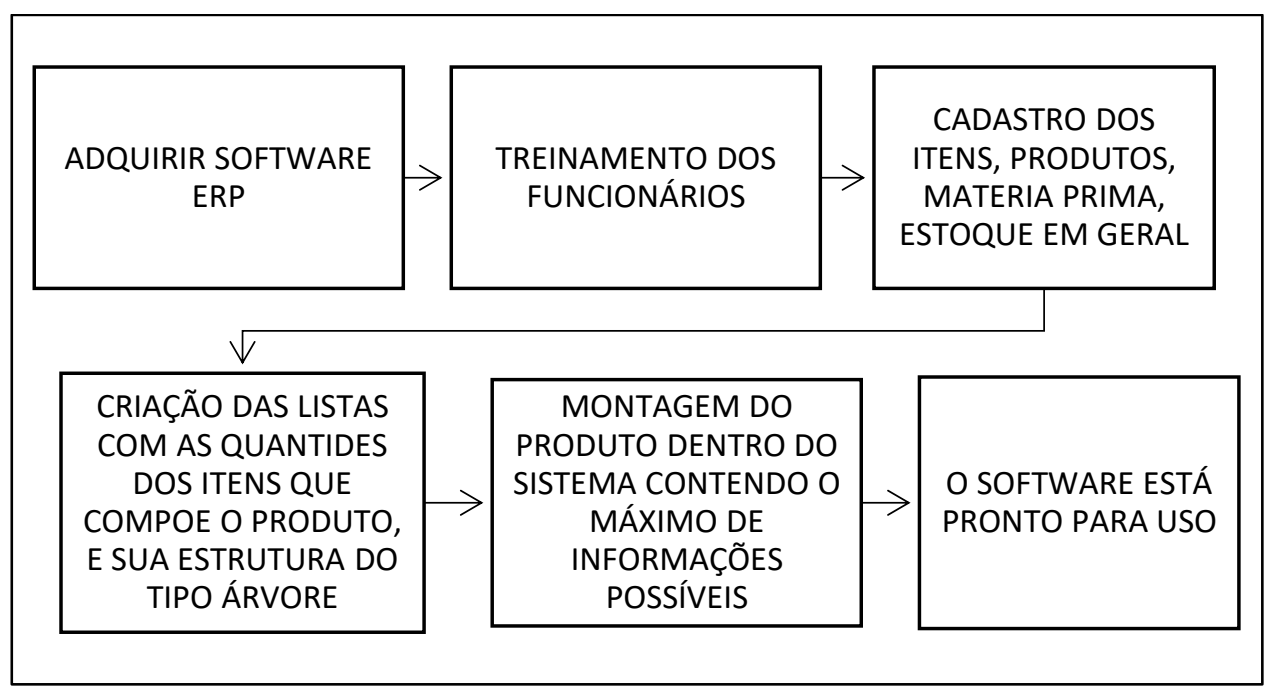

Fonte: Autoria própria. 
Para a implementação do sistema MRP na empresa, será necessário a aquisição do pacote do software MAXIPROD ${ }^{\circledR}$, e posteriormente oferecido um treinamento aos funcionários. Inicialmente deve-se elaborar a lista de materiais dos produtos com maior número de vendas e assim que forem surgindo novos pedidos de produtos, estes devem ser inseridos no sistema a fim de criar uma sólida base de dados para a empresa. Para a criação dessas listas deve ser analisado item a item, e inseridos no sistema.

Após a inserção dos itens no sistema deve ser elaborado a estrutura do produto, onde deve ser caraterizado os itens e subitens e a matéria-prima que compõe o produto, ou se ele e adquirido pronto para montagem. É nesse momento, também, que se coloca as quantidades de cada item para a fabricação de um produto, sendo que o software disponibiliza um recurso bem simples para essa montagem.

Assim, devem ser cadastrados os produtos e matérias-primas em estoque para que o sistema forneça as saídas necessárias para um bom controle de estoques. A partir daí esses produtos também estarão disponíveis para que o setor de vendas também possa integrar ao sistema e possa gerir corretamente esses pedidos de vendas.

\section{CONSIDERAÇÕES FINAIS}

Este estudo teve o objetivo de propor um modelo de implementação de MRP I em uma indústria de implementos rodoviários, identificando a estrutura dos principais produtos, sendo elaborado um modelo de MRP desses produtos selecionados e proposto a implementação do MRP I na empresa.

Diante da proposta apresentada neste trabalho, conclui-se que o estudo atingiu seu objetivo de analisar como o sistema MRP pode auxiliar uma Indústria de implementos rodoviários, no que tange ao gerenciamento de estoque e controle de matéria-prima, além de integrar os setores da empresa e a facilitar o acesso a informações de produção, compras e vendas. Servindo, assim, como base para a gestão da empresa, transmitindo informações em tempo real entre os diversos setores, com a implantação do MRP também garantirá uma reestruturação de seus projetos, com maior nível de detalhamento e organização. Nesse sentido, fica como sugestão para a indústria a implantação do sistema MRP, para realizar o controle do estoque de matéria-prima e o cálculo das necessidades de materiais além de uma integração das informações de toda a empresa.

Para implantação do MRP, deve ser designado um responsável especificamente para esta função para que os objetivos sejam alcançados, também deve haver um empenho da alta direção para que o projeto seja continuado e alcance os objetivos esperados.

As limitações para a realização do estudo ocorram principalmente pela falta de organização e padronização dos projetos estruturais e melhor detalhamento dos implementos, e falta de informações sobre as matérias primas utilizadas na fabricação dos produtos, e também na dificuldade de obter informações sobre processos internos e documentos da empresa. 
Para trabalhos futuros recomenda-se um estudo sobre os tempos de fabricação dos implementos, para que possa ser melhor planejado o tempo de entrega do produto ao cliente uma vez que o produto é feito sob encomenda. Também pode ser implementado, a filosofia $5 \mathrm{~S}$ para uma maior padronização e organização do processo produtivo da empresa.

O presente trabalho, então, abre espaço para que outras empresas dos mais diversos segmentos e tamanhos comecem a se interessar por estudos de melhorias em seus processos de gestão e produção, tornando mais competitivas e se consolidando no mercado. 


\title{
MRP I implementation proposal: case study in a road implementation company
}

\begin{abstract}
This work is the result of a study developed in a company in the industrial sector of road implements and aims at the implementation of a production management system, starting with the implementation of MRP I (Material Resources Planning) for the control of production stocks that works on request. For the study, the three best-selling products were selected, where their structures and material lists were elaborated to exemplify how the result of an ERP system (Material Resource Planning) in the Road Implements sector would be. The study is classified as a case study in which a subject is studied in depth, the objective of the research is descriptive and has a qualitative-quantitative nature. Data collection was done through direct observation, documentary research. After the study, it was possible to confirm what several authors say about production management systems, being a resource that integrates the sectors of the organization and organizes information, streamlining the production process with faster and more accurate information, making organizations a differential that adhere to it.
\end{abstract}

KEYWORDS: Planning and production control. MPR I. ERP. 


\section{REFERÊNCIAS}

ALOINI, D.; DULMIN, R.; MININNO, V. Risk Management in ERP Project Introduction: review of the literature. Information \& Management, v. 44, n. 6, p. 547-567, 2007. crossref

ANFIR. Anuário da Indústria de Implementos Rodoviários. 2018. Disponível em: <http://implementos.net.br/anfir2018/104/>. Acesso em: 27 maio 2019.

AVISON, D.; MALAURENT, J. Impact of cultural differences: A case study of ERP introduction in China. International Journal of Information Management, v. 27, n. 5, p. 368-374, 2007. crossref

BALLOU, Ronald H. Logística Empresarial: transportes, administração de materiais e distribuição física. 1. ed. São Paulo: Atlas, 2010.

BENTO, A. R., Tambosi S. L. e Martin, J. F. M. (2012). A Tecnologia MRP Aplicada na Gestão de Ferramentas de Usinagem no Setor Automobilístico. Contribuição técnica ao 670 Congresso ABM - Internacional, 31 de julho a 3 de agosto de 2012, Rio de Janeiro, RJ, Brasil.

BENTO, A. R., Tambosi, S. L. e Prus, E. M. (2013). Utilização da Tecnologia MRP como melhoria no Planejamento da Produção em uma Indústria Automotiva. Contribuição técnica ao 68으 Congresso Anual da ABM - Internacional, 30 de julho a 2 de agosto de 2013, Belo Horizonte, MG, Brasil. 2013.

BRAGLIA, M.; PETRONI, A. Shortcomings and Benefits Associated With the Implementation of MRP Packages: a survey research. Logistics Information Management, v. 12, n.6, p. 428-438, 1999. crossref

BURBIDGE, J. L. Planejamento e Controle da Produção. 2. ed. São Paulo: Atlas, 1988. 556p.

CHIAVENATO, I. Administração de Materiais: uma abordagem introdutória. Rio de Janeiro: Elsevier, 2005.

CHIAVENATO, Idalberto. Planejamento e Controle da Produção: Planejamento e Controle da Produção. 2. ed. Barueri: Manole, 2011. Idalberto Chiavenato.

CHRISTOPHER, M. Logística e Gerenciamento da Cadeia de Suprimentos. São Paulo: Editora Futura, 1997

CORRÊA, H. L.; GIANESI, I. G. N.; CAON, M. Planejamento, Programação e Controle da Produção MRP II / ERP - Conceitos, Uso e Implementação. 5 ed. São Paulo: Atlas, 2007.

CORRÊA, Henrique L., e Gianesi, Irineu G. N. Just in time, MRP II e OPT: Um enfoque estratégico. São Paulo: Atlas, 1994.

CORRÊA, H.; GIANESI, I.G.N. \& CAON, M. Planejamento, Programação e Controle da Produção. MRPII / ERP. São Paulo: Editora Atlas, 2000. 
CORREA, Henrique Luiz. Planejamento, Programação e Controle da

Produção. São Paulo: Editora Atlas S.a., 2007.

COSTA, Edmilson Ferreira da. DIRETRIZES PARA A ELABORAÇÃO DE UM MANUAL PARA PLANEJAMENTO E CONTROLE DA PRODUÇÃO DE EMPRESAS DE PEQUENO E MÉDIO PORTE. 2010. 51 f. TCC (Graduação) - Curso de Engenharia de Produção, Universidade Federal de Juiz de Fora, Juiz de Fora, 2010. Disponível em: <http://www.ufjf.br/ep/files/2014/07/2010_3_Edmilson.pdf>. Acesso em: 07 set. 2018.

CRESWELL, J. W. Projeto de Pesquisa: métodos qualitativo, quantitativo e misto. $3^{\text {a }}$ ed. Porto Alegre: Artmed, 2010.

DENZIN, N.K.; LINCOLN, Y.S. 2006. O Planejamento da Pesquisa Qualitativa. Porto Alegre, Penso, $432 \mathrm{p}$.

DIAS, M. A. P. Administração de Materiais: princípios, conceitos e gestão. 5. ed. São Paulo: Atlas, 2005.

ERDMANN, Rolf Hermann. Modelo Organizativo para Sistemas de Planejamento e Controle da Produção. Florianópolis UFSC, 1994. Tese (doutorado em engenharia da produção) - programa de pós-graduação em engenharia da produção, UFSC, 1994.

FERNANDES, F. C. F.; GODINHO FILHO, M. Sistemas de Coordenação de Ordens: revisão, classificação, funcionamento e aplicação. Gestão \& Produção, v. 14, n. 2, p. 337-352, 2007. crossref

FONSECA, J. J. S. Metodologia da Pesquisa Científica. Fortaleza: UEC, 2002. Apostila

GERHARDT, Tatiana Engel; SILVEIRA, Denise Tolfo. Métodos de Pesquisa. Porto Alegre: Editora da Ufrgs, 2009. 120 p. Disponível em:

<http://www.ufrgs.br/cursopgdr/downloadsSerie/derad005.pdf>. Acesso em: 07 nov. 2018.

GIL, Antonio Carlos. Métodos e Técnicas de Pesquisa Social. 6. ed. São Paulo: Atlas, 2010. 216 p.

GOLDENSTEIN, Marcelo; ALVES, Marcelo de Figueiredo; AZEVEDO, Rodrigo Luiz Sias de. A Indústria de Implementos Rodoviários e sua Importância para o Aumento da Eficiência do Transporte de Cargas no Brasil. BNDES Setorial, Rio de Janeiro, n. 24, p. 241-260, set. 2006.

GONSALVES, E. P. Conversas Sobre Iniciação à Pesquisa Científica. 4. ed. Campinas, SP: Alínea, 2007. 96p.

GUERRA, R. M. A.; SILVA, M. S. TONDOLO, V. A. G. Planejamento das Necessidades de Materiais: ferramenta para a melhoria do planejamento e 
controle da produção. GEPROS. Gestão da Produção, Operações e Sistemas, Bauru, Ano 9, no 3, jul-set/2014, p. 43-60. Disponível em:

$<$ https://revista.feb.unesp.br/index.php/gepros/article/view/1075/561>. Acesso em: 22 out. 2018. crossref

GUERRA, R. M. de A; SCHUSTER, J. V; TONDOLO. V. A. G. Implantação de um Modelo de MRP em uma Umpresa de Médio Porte do Setor Moveleiro. Revista Gestão Industrial, 2013. Disponível em:

<https://periodicos.utfpr.edu.br/revistagi/article/view/1625/1159>. Acesso em: 22 de out. 2018. crossref

GÜNTHER, H. 2006. Pesquisa Qualitativa Versus Pesquisa Quantitativa: Esta é a questão? Revista Psicologia: Teoria e Pesquisa, 22(2):201-210. crossref

LAW, C. H. C.; NGAI, W. T. E. ERP Systems Adoption: An exploratory study of the organizational factors and impacts of ERP success. Information \& Management, v. 44 , n. 4, p. 418-432, 2007. crossref

LOGÍSTICA, Confederação Nacional dos Trabalhadores em Transporte e Modal Rodoviário. Disponível em: <https://cnttl.org.br/modal-rodoviario>. Acesso em: 14 maio 2019.

LOPES, Rita; MICHEL, Murillo. Planejamento e Controle da Produção e sua Importância na Administração. Revista Científica Eletrônica de Ciências Contábeis. v. 5, n. 9, maio 2007.

LUTOSA, Leonardo et al. Planejamento e Controle da Produção. Rio de Janeiro: Elsevier, 2008.

MARTINS, Petrônio G; LAUGENI, Fernando Piero. Administração da Produção. 2 ed. São Paulo: Saraiva, 2005.

MAXPROD INFORMÁTICA INDUSTRIAL, ERP Industrial. Disponível em: <https://www.maxiprod.com.br/erp />. Acesso em: 20 out. 2019.

MOREIRA, D. A. Administração da Produção e Operações. São Paulo: Pioneira Thomson Learning, 2001.

NORMAN, E. DANIEL, "Distribution Requeriments Planning: Problems and Promises", em Logistics: Contribution and Control, ed. Patrick Gallagher, Proceedings of the 1983 Logistics Resource Forum (Cleveland: Leaseway Transportation Corp., 1983), pág. 213.

OLIVEIRA, Lindomar Subtil de; HATAKEYAMA, Kazuo. Um Estudo Sobre a Implantação de Sistemas ERP: pesquisa realizada em grandes empresas industriais. Production, [s.I.], v. 22, n. 3, p.596-611, 2 ago. 2012. crossref

PEINADO, Jurandir. Administração da Produção. Cutitiba: Isbn, 2007. 750 p. 
PEINADO, Jurandir; GRAEML, Alexandre Reis. Administração da

Produção: Operações Industriais e de Serviços. Curitiba: Unicenp, 2007. 750 p.

Disponível em: <http://paginapessoal.utfpr.edu.br/jurandirpeinado/livro-

administracao-da-producao/livro-administracao-da-

producao/livro2folhas.pdf/at_download/file>. Acesso em: 20 out. 2018.

PLOSSL, G. W. Administração da produção: como as empresas podem aperfeiçoar as operações a fim de competirem globalmente. São Paulo: Makron Books, 1993. 223p.

RIBEIRO, Marjori Schmit. A PERFORMANCE DO SISTEMA SAP NOS DIFERENTES NÍVEIS DO PROCESSO DECISÓRIO. 2016. 22 f. Monografia (Especialização) - Curso de Controladoria e GestÃo Empresarial, Universidade Regional do Noroeste do Estado do Rgs, ljui, 2016. Disponível em:

<http://bibliodigital.unijui.edu.br:8080/xmlui/bitstream/handle/123456789/3954 /Marjori\%20Schmit\%20Ribeiro.pdf?sequence=1>. Acesso em: 04 out. 2018.

RUSSOMANO, Victor Henrique. PCP: Planejamento e Controle da Produção. 6 Edição. São Paulo: Editora Pioneira, 2000.

SLACK, N.; CHAMBERS, S.; JOHNSTON, R. Administração da Produção, 3. Ed. São Paulo: Atlas, 2009.

SLACK, Nigel. Administração da produção. SÃo Paulo: Editora Atlas S.a., 2002. SOLON, A. S.; FINOTTI, M. S. Desenvolvimento e Implantação do MRP: Um Estudo de Caso. 2010. Disponível em:

<http://www.abepro.org.br/biblioteca/enegep2010_TN_STO_113_740_15850.pd f>. Acesso em: 22 out. 2018.

THIOLLENT, M. Metodologia da Pesquisa-ação. 16 ed. São Paulo: Cortez, 2008.

TUBINO, D. F. Manual de Planejamento e Controle da Produção. 2a Edição. São Paulo: Editora Atlas, 2000.

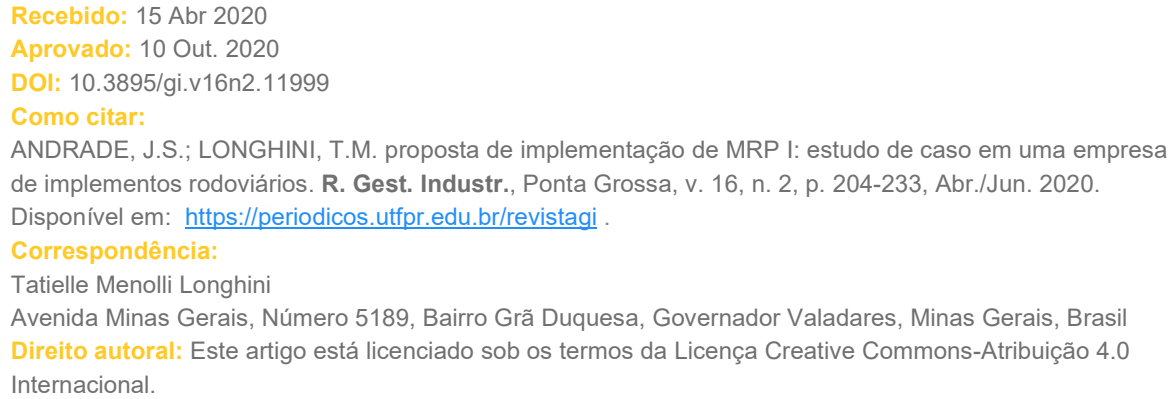

